\title{
LA POBLACIÓN DESOCUPADA EN LA CIUDAD DE ELCHE
}

\author{
José Antonio Larrosa Rocamora
}

\section{RESUMEN}

El Censo de Población es, después del extraordinario empobrecimiento del Padrón de Habitantes, y ante la insuficiencia de criterios espaciales y temáticos de otras fuentes estadísticas, la única publicación que puede mostrar la realidad sociolaboral de los distintos espacios urbanos (los barrios). El presente artículo es un ejemplo de utilización del Censo en el estudio del paro de una ciudad de tamaño medio y de marcado carácter industrial, Elche, a dos niveles espaciales: en primer lugar, se analizan las características sociodemográficas que definen a la población desocupada del municipio ilicitano, a partir de la información existente en el Censo de Población de 1991 (el sexo, la edad, el estado civil, la instrucción y la experiencia profesional), y en contraposición al perfil del parado de Alicante (capital y provincia); en segundo lugar, se muestra la heterogénea configuración social y laboral del espacio intraurbano, resultado de una segregación residencial compleja, que se ha visto favorecida por la masiva llegada de inmigrantes a Elche desde mediados de los años 50.

Palabras clave: Tasa de paro, Censo de Población de 1991, municipio de Elche.

\section{ABSTRACT}

The population Census is, after the extraordinary impoverishment of the Census of Inhabitants, and since the insufficiency of spatial and thematical criteria from other statistical sources, the only publication that can show the sociolaboral reality of the different urban spaces (the quarters). This article is an instance of the use of the Census in the study of unemployment in a mid-size city and with a fundamentally industrial nature, Elche, in two spatial layers: first of all, sociodemographic features which define the population unemployed in the illicitan municipality are analysed according to the existing information in the Population Census of 1991 (sex, age, civil status, education and professional experience), and in comparison with the outline of the unemployed inhabitants of Alicante (capital and province); in the second place, the heterogenic social and labour configuration of the intraurban space is shown, as the result of the complex residential segregation, which has been favoured by the massive arrival of immigrants to Elche from the mid-fifties.

Key words: unemployment rate, Census of Population of 1991, municipality of Elche. 


\section{Introducción}

El espectacular crecimiento de la población desocupada a raíz de la crisis económica de los años 70, ha convertido la falta de empleo en una de las mayores preocupaciones de la sociedad española. Prueba de ello es la proliferación de estudios multidisciplinares sobre el paro, y el progresivo aumento de información de la Encuesta de Población Activa (EPA), fuente estadística por excelencia en la investigación y en el control de las distintas magnitudes del mercado de trabajo.

No obstante, detrás de las grandes cifras del desempleo se esconde una realidad socioespacial mucho más compleja y desconocida, de la que es protagonista la ciudad y sus barrios. Pese a la consolidación de una sociedad eminentemente urbana y a la cada vez mayor heterogeneidad interna de las ciudades de tamaño medio y grande, los estudios del paro a una escala inferior a la provincial, carecen casi por completo de una publicación capaz de aportar claridad al conocimiento de este problema social.

El objetivo del presente artículo es mostrar la información y las posibilidades de análisis que ofrece el Censo de Población de 1991 en este ámbito de estudio, y su aplicación en la comprensión del desempleo de una ciudad de tamaño medio y de marcado carácter industrial, Elche.

La EPA es una encuesta muestral de enorme interés, tanto por la exhaustividad y fiabilidad de sus datos, como por el manejo de conceptos homologados internacionalmente, que hacen posible la extrapolación de sus cifras a un ámbito supraestatal. Sin embargo, tiene una escasa utilidad para los estudios urbanos, ya que no dispone de información a esta escala. Los datos de demandantes de empleo registrados por el Instituto Nacional de Empleo presentan, por su parte, otros inconvenientes: en muchas ocasiones carecen de un referente espacial claro, ya que las oficinas de empleo no están necesariamente circunscritas a una entidad municipal (pueden atender a parados de varios municipios); su fiabilidad puede quedar menguada, ya que la función de este organismo es estrictamente subsidiaria; como no registran a los activos, son insuficientes para hallar tasas de paro, de manera que pierden interés, etc.

Así pues, el Censo de Población es, después del extraordinario empobrecimiento del Padrón de Habitantes ${ }^{1}$, y a pesar de la insuficiencia de criterios espaciales y temáticos que todavía hoy adopta el Instituto Nacional de Estadística ${ }^{2}$, la única fuente que puede mostrar la realidad sociolaboral de los distintos espacios urbanos (los barrios). Además, la posibilidad de contar con datos en formato digital, gracias a la publicación del programa Info Censos, por el Instituto Valenciano de Estadística, facilita considerablemente la otrora laboriosa tarea de cruce de datos. Esta fuente distingue, para cada una de las secciones padronales, a los parados, por sexos y experiencia laboral, y para el conjunto del municipio, además, por grupos de edad, estado civil y nivel de instrucción; pero desgraciadamente «olvida» otros datos de enorme interés, como el de parados de larga duración, o el de desocupados por profesiones.

El presente artículo tiene también un objetivo empírico: el estudio de la situación laboral del municipio de Elche y de sus barrios, y su comparación con una realidad socioeconómica totalmente contrapuesta a la industrial de Elche, la terciaria de la ciudad de Alicante

1 El Padrón de 1986 fue el último que incorporó datos sobre la condición económica de la población.

2 LÓPEZ FERNÁNDEZ, B.: «La gradación del envejecimiento en los espacios intraurbanos. Estructuras demográficas y crecimiento urbano en Gijón», Ería, 1988, pp. 201-234. 
(y en gran medida de la Provincia). Desde 1950, la estructura profesional de la población ilicitana ha acogido un continuo descenso de activos agrarios, y una importante expansión de terciarios, demandados por las necesidades de servicios de la industria del calzado, y por el crecimiento del volumen de población urbana. El sector secundario, por su parte, ha perdido empleo relativo desde la crisis de los años setenta. Fruto de esta evolución, y sobre todo de los cambios que desde hace unos lustros está experimentando la industria ilicitana del calzado, en el municipio de Elche están bien representados el paro, la flexibilidad laboral, y el trabajo sumergido.

Cuadro 1

EVOLUCIÓN DE LA ESTRUCTURA PROFESIONAL. ELCHE

\begin{tabular}{|c|c|c|c|c|c|}
\hline Años & $\begin{array}{c}\text { T. de } \\
\text { actividad }\end{array}$ & Primario & Secundario & Terciario & Mal especificado \\
\hline 1950 & $54.4^{1}$ & 29.7 & 51.7 & 15.2 & 3.4 \\
1960 & $53.9^{1}$ & 22.8 & 56.5 & 17.3 & 3.4 \\
1970 & $40.3^{2}$ & 11.9 & 58.6 & 26.6 & 1.8 \\
1981 & $51.2^{2}$ & $7.4^{*}$ & $59.1^{*}$ & $33.6^{*}$ & -- \\
1991 & $53.8^{2}$ & $4.5^{*}$ & $51.1^{*}$ & $44.3^{*}$ & -- \\
\hline
\end{tabular}

1 Activos sobre la población de 14 y más años.

2 Activos de 16 y más años, sobre la población de 16 y más años.

*Los datos publicados en los censos de población de 1981 y 1991 están referidos a la población ocupada de 16 y más años, no a la activa.

Fuente: GOZÁLVEZ PÉREZ, V. La ciudad de Elche, 1976, para los datos de sectores económicos de 1950, 1960 y 1970. Censos de Población de España; 1950, 1960, 1970, 1981 y 1991.

\section{Características del desempleo en el municipio de Elche}

El incremento de los niveles del desempleo experimentado en las últimas décadas en Elche no es producto de un ciclo económico, sino que obedece a causas estructurales. La explicación del progresivo aumento del paro en esta ciudad se apoya, sin duda, en la disminución del empleo generado por la industria del calzado (cuadro 3), que ocupaba un importante contingente de mano de obra, y en la escasa capacidad de absorción de empleo del sector terciario ilicitano, constreñido por la potente actividad comercial y de servicios de la vecina ciudad de Alicante. Aún así, en el periodo que va de 1986 a 1991 (años de publicación del Padrón Municipal de Habitantes y del Censo de Población, fuentes utilizadas en este estudio), se crearon 6.000 nuevos empleos, cifra que sin embargo no ha servido para cubrir el crecimiento de la población activa, de manera que el volumen de parados ha aumentado en el citado periodo un $29 \%$, al pasar de 16.602 a 21.373 desocupados.

Además, como se puede apreciar en el cuadro 2, el crecimiento del paro ha sido mayor en Elche que en el conjunto de la Provincia de Alicante. La tasa de paro de la población ilicitana ha pasado del $25.9 \%$ de 1986 , al $28.6 \%$ de 1991 , mientras que la tasa de la provincia lo ha hecho del $20.9 \%$ al $22.4 \%$, lo que sitúa el aumento del desempleo en 2.7 y 1.5 puntos respectivamente. La ciudad de Alicante, por el contrario, ha acogido en este lapso de tiempo un ligero descenso del paro. En la composición del paro por sexos ha habido 
alguna variación interesante, ya que al escaso aumento de la desocupación en los varones, ha correspondido una importante expansión del paro femenino, básicamente por el crecimiento de la incorporación de la mujer a la actividad, que se ha producido en unos términos similares a los del paro. Sin embargo, a pesar de la existencia de estas elevadas tasas de paro, el ambiente social de la ciudad de Elche no parece perturbado, salvo en alguna zona en la que excepcionalmente intervienen otros factores, como la drogadicción o la delincuencia. En cualquier caso, es preciso recordar la corrección de la autodeclaración de parado con la ocupación en economía sumergida, bien representada en el municipio.

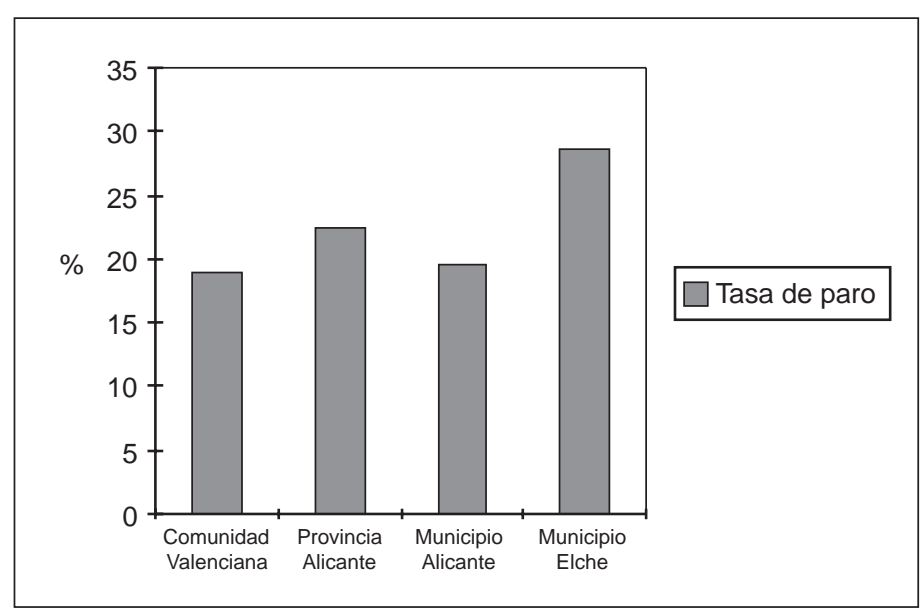

Fuente: Elaboración propia a partir de los datos del Censo de Población de 1991.

GráfICO 1. Tasas de paro de Elche, Comunidad Valenciana, Provincia de Alicante y Alicante ciudad en 1991.

Para entender esta situación sociolaboral es obligado remontarse a las transformaciones que se produjeron en la organización de la producción industrial a raíz de la crisis económica de los años setenta, y que tiene su origen en la decadencia del modelo de producción fordista.

Cuadro 2

EVOLUCIÓN DE LAS TASAS DE PARO Y DE ACTIVIDAD DE LA PROVINCIA DE ALICANTE, ALICANTE CIUDAD, Y ELCHE

\begin{tabular}{|c|c|c|c|c|c|c|c|c|c|c|c|c|c|c|c|c|c|c|}
\hline & \multicolumn{6}{|c|}{ ELCHE } & \multicolumn{6}{|c|}{ PROVINCIA } & \multicolumn{6}{|c|}{ ALICANTE } \\
\hline & \multicolumn{3}{|c|}{$\begin{array}{c}\text { TASA DE } \\
\text { PARO }\end{array}$} & \multicolumn{3}{|c|}{$\begin{array}{c}\text { TASA DE } \\
\text { ACTIVIDAD }\end{array}$} & \multicolumn{3}{|c|}{$\begin{array}{c}\text { TASA DE } \\
\text { PARO }\end{array}$} & \multicolumn{3}{|c|}{$\begin{array}{c}\text { TASA DE } \\
\text { ACTIVIDAD }\end{array}$} & \multicolumn{3}{|c|}{$\begin{array}{c}\text { TASA DE } \\
\text { PARO }\end{array}$} & \multicolumn{3}{|c|}{$\begin{array}{c}\text { TASA DE } \\
\text { ACTIVIDAD }\end{array}$} \\
\hline & $\mathrm{V}$ & $\mathrm{M}$ & $\mathrm{T}$ & V & $\mathrm{M}$ & $\mathrm{T}$ & V & $\mathrm{M}$ & $\mathrm{T}$ & V & M & $\mathrm{T}$ & V & $\mathrm{M}$ & $\mathrm{T}$ & $\mathrm{V}$ & $\mathrm{M}$ & $\mathrm{T}$ \\
\hline 1986 & 23.6 & 31.5 & 25.9 & 75.6 & 29.4 & 52.2 & 18.0 & 28.1 & 20.9 & 71.9 & 26.9 & 48.7 & 19.7 & 26.7 & 21.7 & 71.6 & 29.0 & 48. \\
\hline 1991 & 25.0 & 36.0 & 28.6 & 73.9 & 34.4 & 53.8 & 18.1 & 30.8 & 22.4 & 70.1 & 33.4 & 51.2 & 15.2 & 25.6 & 19.0 & 69.1 & 36.0 & 51.6 \\
\hline
\end{tabular}

Fuente: Elaboración propia a partir de los datos del Censo de Población de 1991, y del Padrón Municipal de Habitantes de 1986. 
Este hecho tiene en Elche una imagen paradigmática, debido a las características estructurales de la industria del calzado, que acumula el capital, básicamente, de las plusvalías generadas por el trabajo intensivo de la mano de obra. Desde mediados de los setenta, el modelo de acumulación capitalista comienza a sustentarse en un nuevo proceso productivo, más flexible y con mayores avances técnicos, y en una nueva regulación de las relaciones laborales, fruto del uso más intensivo del capital en detrimento de la fuerza de trabajo ${ }^{3}$. Esto se traduce en la manufactura ilicitana en una mayor separación física de las fases productivas del calzado (se recurre a lo que algunos autores han llamado fabricación difusa), en la atomización del tejido fabril, y por último, en la génesis de una nueva situación laboral, caracterizada por la reducción y por la precarización (subcontratación, prácticas informales, trabajo temporal, etc.) del volumen de empleo industrial, lo que ha dado lugar, directa e indirectamente, al aumento del número de desocupados.

Cuadro 3

EL EMPLEO Y LOS COSTES LABORALES DEL SECTOR CALZADO DE LA C. VALENCIANA

\begin{tabular}{|c|c|c|c|c|c|c|}
\hline Años & \multicolumn{3}{|c|}{ PERSONAS EMPLEADAS } & \multicolumn{3}{c|}{ COSTES LABORALES } \\
\hline & Total & $\mathbf{( 1 )}$ & $\mathbf{( 3 )}$ & Total* & $\mathbf{( 1 )}$ & (2) \\
\hline 1970 & 40.675 & 100.0 & 20.5 & 6.409 & 100.0 & 157.576 \\
1975 & 49.700 & 122.2 & 24.6 & 12.006 & 187.3 & 241.578 \\
1980 & 34.990 & 86.0 & 21.4 & 11.119 & 173.5 & 317.781 \\
1985 & 19.261 & 47.4 & 19.1 & 6.152 & 96.0 & 319.393 \\
1991 & 15.740 & 38.7 & 13.7 & 5.524 & 86.2 & 350.940 \\
\hline
\end{tabular}

1 Índice de variación respecto al primer año de la serie considerada.

2 Valor considerado en pts / empleados.

3 Total de empleados / total de empresas.

* En millones de pts. constantes.

Fuente: SEBASTIÁ ALCARAZ, R., «La industria del calzado en la provincia de Alicante: características de su evolución reciente (1970-1991)», Investigaciones Geográficas, nº 18, 1997, pp. 81-98.

Es cierto que la economía y el trabajo sumergido (que daba, y da empleo a un número importante de «parados» oficiales) ya se utilizaban en la etapa desarrollista de los años 60 y 70; sin embargo, durante este periodo servía como estrategia de consolidación de la actividad industrial, mientras que en la actualidad el recurso al sector informal se ha convertido, fundamentalmente, en un medio para asegurar la supervivencia de muchas empresas ${ }^{4}$. Este cariz de «necesidad», junto con las altas tasas de paro y la actual coyuntura neoliberalista, es lo que proporciona a las prácticas informales una cierta legitimidad social y administrativa.

3 BAYLINA, Mireia: «Geografia de la producció, flexibilitat en el mercat de treball i relacions de gènere. L'exemple del treball industrial a domicili», Cuadernos de Geografía, nº 55, 1994, pp. 45-61.

4 Enric Sanchis apunta, además de la supervivencia, otras causas secundarias en la utilización de la economía sumergida, como la vía para financiar la modernización tecnológica, o sencillamente para obtener superbeneficios, en La otra economía. Trabajo negro y sector informal, 1988, p. 420. 
Por otra parte, la flexibilización del mercado laboral, favorecida en Elche por la conjunción de una serie de aspectos socioeconómicos, entre los que destacan la escasa fuerza del movimiento sindical, la existencia de un importante volumen de mano de obra secundaria (mujeres y jóvenes principalmente), y el comportamiento casi temporal de muchas de las empresas de calzado, ha dado lugar a la creación de una gran bolsa de «empleados flexibles», formada por parados, trabajadores oficialmente no activos (estudiantes, amas de casa, etc.) y empleados eventuales.

\section{Características sociodemográficas de la población desocupada de Elche}

Como es sabido, no se puede hablar del desempleo de forma unívoca, ya que la intensidad y las consecuencias generadas por esta situación varían de unos grupos sociales a otros, y de unos lugares a otros, en función de la estructura de la demanda del mercado y de aspectos demográficos, sociales, etc. Entre estos destacan las características que definen el perfil del parado (la edad, el sexo, la experiencia, la formación, etc.), y los mecanismos sociales que cada comunidad y cada individuo tienen para amortiguar los efectos derivados de la desocupación.

\subsection{La edad y el sexo de la población desocupada}

La distinción del paro por sexos arroja porcentajes muy superiores en las mujeres. En efecto, la tasa de desempleo de la población femenina de Elche es de un 36\%, cifra sensiblemente superior a la de la provincia de Alicante, $30.8 \%$, y mucho más alta que la de la capital alicantina, que se sitúa en torno al $25 \%$. Por otra parte, todas estas tasas son considerablemente más elevadas que las del paro masculino $(25 \%, 18 \%$, y $15 \%$ respectivamente, para cada uno de los espacios citados), a pesar de que la participación de la mujer en la actividad es, en todos estos territorios, muy inferior a la del hombre. Esta realidad excede el ámbito del espacio que estamos estudiando, pues de hecho, en 1988 once de los doce países integrantes de la por entonces CEE presentaban también este estado de desigualdad laboral ${ }^{5}$.

No obstante, en Elche, como en todos estos territorios, la mayor parte de los parados son hombres, ya que de los 21.373 activos sin ocupación que tenía Elche en 1991, 12.633 (el 60\%) eran varones, y 8.700 mujeres. Sin embargo, si relacionamos estas cifras absolutas con los porcentajes de activos de uno y otro sexo, llegamos a la conclusión, ya apuntada, de que la mujer se halla en una situación de discriminación laboral. Esto es así porque a pesar de que sólo el 34,4\% de las ilicitanas participa en la actividad económica «oficial», más de un tercio de las mismas se encuentra sin empleo, en tanto que entre los hombres la tasa de actividad $^{6}$ se eleva hasta el $75 \%$, y sin embargo el paro «sólo» afecta a una cuarta parte de los mismos. Además, el llamado «paro desanimado» ${ }^{7}$, es decir, el resultante de la salida de la actividad por imposibilidad de encontrar empleo, afecta sobre todo a la mujer;

5 PAZOS MORÁN, M. «Las mujeres y el empleo en España. Elementos para un balance 1987-1990», Economía y sociología del trabajo, $\mathrm{n}^{\circ} 13-14,1991, \mathrm{pp} .88-102$.

6 La tasa de actividad relaciona la población ocupada y en paro de 16 años o más, con el total de habitantes mayores de esa edad.

7 RAYMOND, JL., y CASTAÑER, JM., «Algunos rasgos de la actividad y del paro según la Encuesta de condiciones de vida y trabajo en España», Fundación FIES, n 33, 1988, pp. 1-17. 
seguramente porque el trabajo femenino, por su condición secular de empleo secundario, ha mantenido, y mantiene, una constante fluctuación en la actividad, en función tanto de la coyuntura económica global como de su edad, estado civil, etc. ${ }^{8}$

Cuadro 4

TASA DE PARO POR GRUPOS DE EDAD Y SEXO. ELCHE, 1991

\begin{tabular}{|c|c|c|c|}
\hline Grupos de edad & V & M & Total \\
\hline $16-19$ & 42.5 & 44.5 & 43.5 \\
$20-24$ & 31.8 & 39.2 & 35.1 \\
$25-29$ & 25.8 & 38.3 & 30.7 \\
$30-34$ & 22.5 & 35.4 & 26.7 \\
$35-39$ & 21.5 & 30.3 & 24.0 \\
$40-44$ & 18.5 & 26.7 & 20.6 \\
$45-49$ & 20.2 & 26.2 & 21.5 \\
$50-54$ & 23.7 & 28.0 & 24.5 \\
$55-59$ & 25.8 & 30.2 & 26.6 \\
$60-64$ & 23.3 & 31.9 & 24.9 \\
$65-69$ & 21.1 & 39.2 & 26.8 \\
$70-74$ & 29.0 & 38.1 & 32.7 \\
75 y + & 31.0 & 64.0 & 46.3 \\
\hline TOTAL & $\mathbf{2 5 . 1}$ & $\mathbf{3 5 . 8}$ & $\mathbf{2 8 . 6}$ \\
\hline Cifras totales absolutas & $\mathbf{1 2 . 6 3 3}$ & $\mathbf{8 . 7 4 0}$ & $\mathbf{2 1 . 3 7 3}$ \\
\hline
\end{tabular}

Fuente: Elaboración propia a partir de los datos del Censo de Población de 1991.

El gráfico 2 y el cuadro 4 sintetizan la relación entre el desempleo y las variables edad y sexo. A los 16-19 años, el desempleo alcanza para ambos sexos la proporción más elevada (a excepción del 64\% de las mujeres mayores de 75 años), al mismo tiempo, en esta cohorte las diferencias laborales entre mujeres y hombres quedan prácticamente anuladas, ya que la tasa de paro y la tasa de actividad (ver gráfico 3) presentan porcentajes semejantes. Así pues, los más jóvenes forman un único colectivo que ha reforzado en los últimos años su condición de grupo de empleo secundario, forzado, sin duda, por un sistema económico que los somete a los vaivenes de la actividad económica, ya que los puestos de trabajo que ocupa la población joven son, desde el punto de vista laboral, los más inestables.

8 SANTILLANA DEL BARRIO, I., «Paro y estructura ocupacional de la población activa», Papeles de Economía Española, $\mathrm{n}^{\circ}$ 8, Madrid, 1981, pp. 176-193. 


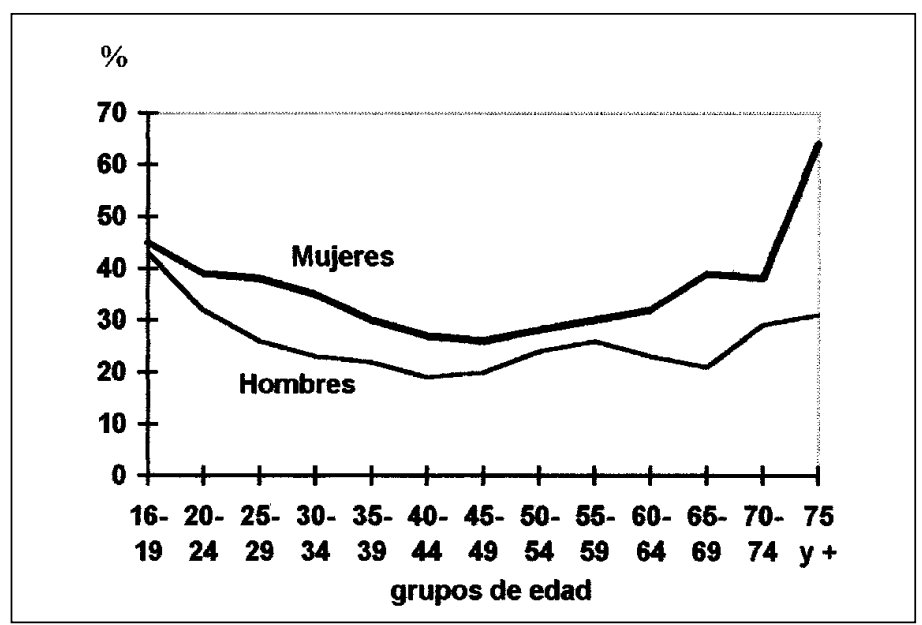

Fuente: Elaboración propia a partir de los datos del Censo de Población de 1991.

GRÁFICO 2. Tasas de paro por grupos de edad y sexo. Elche. 1991.

El descenso del desempleo, que se produce desde la primera edad potencialmente activa, se da con mayor intensidad entre los hombres, debido a que, como ya hemos dejado entrever, la desocupación femenina está mucho más sujeta al comportamiento de la oferta de trabajo. Las tasas de paro más bajas se alcanzan, para ambos sexos, entre los 40 y los 49 años, aunque en cifras absolutas los grupos más productivos (los que presentan un mayor número de ocupados) son los comprendidos entre los 20 y 24 años en las mujeres, y los 30 y 34 años en los hombres. El desempleo comienza de nuevo a crecer en ambos sexos a partir de los 50 años. No obstante, aunque el paro masculino aumenta hasta situarse por encima de la media entre los que tienen de 55 a 59 años, disminuye en el exiguo grupo de activos de 60 a 69 años, seguramente debido al extraordinario decrecimiento que la jubilación provoca sobre las tasas de actividad. Estas personas que están al final de su vida laboral forman uno de los colectivos más afectados por el desempleo; básicamente porque su rendimiento esperado es decreciente y suelen recibir sueldos más elevados ${ }^{9}$.

Como se puede ver en el cuadro 5, aunque las tasas de paro de provincia y capital son siempre bastante más bajas que las de Elche, las diferencias quedan prácticamente anuladas en la población joven de 16 a 24 años de edad. Esto es consecuencia de la mayor flexibilidad del mercado laboral ilicitano, que genera una rotación de puestos de trabajo superior a la de otros territorios. Sin embargo, esa eventualidad laboral, cifrada en 19.275 empleos no fijos (un 36\% de la población ocupada de Elche; más de diez puntos por encima del porcentaje de la ciudad de Alicante) hace que las tasas de paro se mantengan muy por encima del $20 \%$ en los otros tramos de edad. En Alicante, en cambio, una vez superadas las dificultades para encontrar el primer empleo (el $27.1 \%$ de los desocupados de Alicante buscan su primer empleo, frente al $19.9 \%$ de Elche), las posibilidades de conseguir un trabajo

9 GARCÍA, J., POLO, C., y RAYMOND, JL., «Principales rasgos del desempleo masculino en España», Papeles de Economía Española, nº 26, 1986, pp. 81-107. 
Cuadro 5

TASAS DE PARO Y DE ACTIVIDAD DE LA PROVINCIA DE ALICANTE, ALICANTE CIUDAD, Y ELCHE, POR GRUPOS DE EDAD Y SEXO, 1991

\begin{tabular}{|c|c|c|c|c|c|c|c|c|c|c|c|c|c|c|c|c|c|c|}
\hline \multirow{3}{*}{$\begin{array}{l}\text { Grupo de } \\
\text { Edad }\end{array}$} & \multicolumn{6}{|c|}{ PROVINCIA } & \multicolumn{6}{|c|}{ ALICANTE } & \multicolumn{6}{|c|}{ ELCHE } \\
\hline & \multicolumn{3}{|c|}{$\begin{array}{c}\text { TASA DE } \\
\text { PARO }\end{array}$} & \multicolumn{3}{|c|}{$\begin{array}{c}\text { TASA DE } \\
\text { ACTIVIDAD }\end{array}$} & \multicolumn{3}{|c|}{$\begin{array}{c}\text { TASA DE } \\
\text { PARO }\end{array}$} & \multicolumn{3}{|c|}{$\begin{array}{c}\text { TASA DE } \\
\text { ACTIVIDAD }\end{array}$} & \multicolumn{3}{|c|}{$\begin{array}{l}\text { TASA DE } \\
\text { PARO }\end{array}$} & \multicolumn{3}{|c|}{$\begin{array}{c}\text { TASA DE } \\
\text { ACTIVIDAD }\end{array}$} \\
\hline & $\mathrm{V}$ & M & $\mathrm{T}$ & $\mathrm{V}$ & $\mathrm{M}$ & $\mathrm{T}$ & $\mathrm{V}$ & $\mathrm{M}$ & $\mathrm{T}$ & $\mathrm{V}$ & $\mathrm{M}$ & $\mathrm{T}$ & $\mathrm{V}$ & $\mathrm{M}$ & $\mathrm{T}$ & $\mathrm{V}$ & $\mathrm{M}$ & $\mathrm{T}$ \\
\hline $16-24$ & 31.8 & 41.1 & 36.0 & 62.3 & 53.0 & 57.7 & 31.7 & 40.7 & 35.6 & 52.3 & 46.0 & 49.2 & 35.3 & 41.2 & 38.0 & 65.1 & 57.7 & 61.5 \\
\hline $25-54$ & 14.6 & 26.8 & 18.5 & 94.8 & 42.9 & 68.8 & 11.4 & 21.3 & 14.9 & 94.9 & 50.0 & 71.7 & 22.2 & 33.0 & 25.4 & 95.6 & 39.6 & 67.4 \\
\hline $55 \mathrm{y}+$ & 17.5 & 23.4 & 19.0 & 31.3 & 8.0 & 18.4 & 14.9 & 17.1 & 15.5 & 33.7 & 9.1 & 19.6 & 24.8 & 32.2 & 26.2 & 34.1 & 6.6 & 19.4 \\
\hline Total & 18.1 & 30.8 & 22.4 & 70.1 & 33.4 & 51.2 & 15.2 & 25.6 & 19.0 & 69.1 & 36.0 & 51.6 & 25.0 & 36.0 & 28.6 & 73.9 & 34.4 & 53.8 \\
\hline
\end{tabular}

Fuente: Elaboración propia a partir de los datos del Censo de Población de 1991.

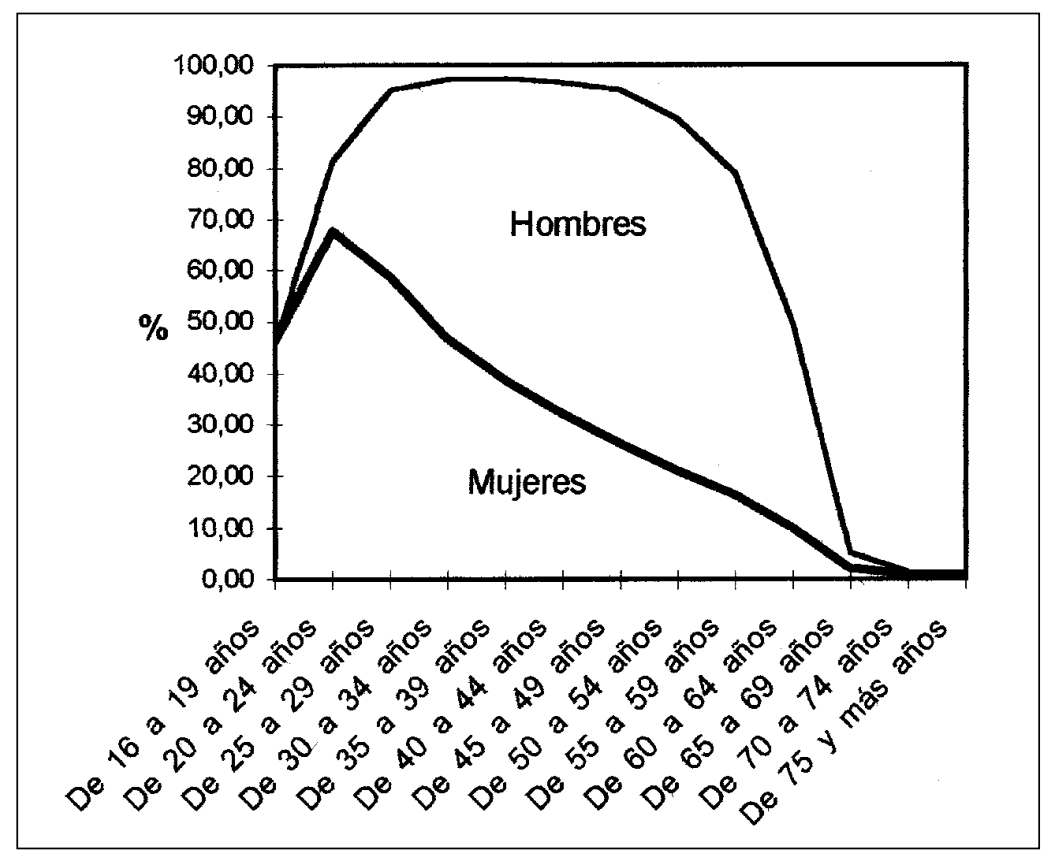

Fuente: Elaboración propia a partir de los datos del censo de Población de 1991.

GráfICO 3. Tasa de actividad por sexo y grupos de edad. Elche, 1991. 
estable aumentan considerablemente, como se pone de manifiesto en la brusca caída de las tasas del paro después de los 24 años.

Todos estos aspectos contribuyen a que la tasa de actividad de los jóvenes ilicitanos (61.5\%) sea bastante más alta que la de los jóvenes de la ciudad de Alicante (49.2\%), y algo mayor que la de los del conjunto de la provincia (57.7\%). Pero en esta cuestión intervienen otros factores: la mayor proporción de jóvenes universitarios de 20 a 29 años en Alicante (un $23.2 \%$, frente al $12.2 \%$ de Elche o el $15 \%$ de la provincia), y la mejor situación laboral del sustentador familiar en esta ciudad (sólo el 9.9\% de los hombres no solteros de Alicante están en paro, frente al $21.2 \%$ de los no solteros de Elche), también contribuyen a retrasar la entrada de los alicantinos en el mercado laboral.

Entre los individuos de mediana edad, de 25 a 54 años, la tasa de actividad es menor en Elche, básicamente por la escasa participación laboral de las mujeres ilicitanas (un $39.6 \%$, frente a un $50 \%$ en Alicante o un $42.9 \%$ en la provincia), aunque una parte importante de ellas trabaja extraoficialmente en los talleres clandestinos del calzado. A estas diferencias también contribuye el hecho de que el motor de la economía de la ciudad de Alicante (y en gran medida de la provincia) sea el sector servicios, ya que éste emplea más mujeres que el sector industrial; a nivel provincial, la ocupación de la mujer en los servicios representa casi el $40 \%$, mientras que en la industria este porcentaje se reduce al $26 \%$.

\subsection{El estado civil y el nivel de instrucción de la población desocupada}

El estado civil, por su relación con los roles sociales que las mujeres y los hombres tienen asignados, constituye, todavía hoy, uno de los aspectos fundamentales para comprender el grado de participación de la población en el mercado laboral, y por consiguiente, para interpretar los valores de la desocupación.

El cuadro 6 nos permite comparar para cada sexo y grupo de edad, la tasa de paro y la tasa de actividad, de acuerdo con el estado civil de la persona. Según las tasas de paro totales, los solteros de ambos sexos son los que sufren en mayor medida el problema de la desocupación. Aun así, las características de la actividad y del desempleo son, de uno a otro sexo, completamente opuestas. En efecto, entre los hombres solteros y los no solteros ${ }^{10}$ las tasas de paro varían considerablemente, del $34.5 \%$ de los primeros al $21 \%$ de los segundos, mientras que la tasa de actividad sólo es superior para los no solteros en 6 puntos. En cambio, las cifras del paro femenino apenas distinguen uno de otro estado civil, todo lo contrario que la actividad, en la que la tasa de las solteras (60.2\%) supera en más de 30 puntos la exigua tasa (el $25.8 \%$ ) de las no solteras.

Las causas que explican estas diferencias están relacionadas, intrínsecamente, con el comportamiento social establecido en un ámbito cultural que excede el pequeño espacio que estamos estudiando. Por ejemplo, en los varones el trabajo siempre ha sido una necesidad, o una obligación (por eso las tasas de actividad siempre son elevadas), fuese cual fuese la condición civil del individuo, aunque parece comprobado que el vínculo matrimonial refuerza los deseos de encontrar y/o mantener el empleo ${ }^{11}$, de ahí que la tasa de paro sea bastante más baja entre los no solteros. En las mujeres casadas, la crianza de los hijos y el papel secular de cónyuge del sustentador familiar hace que, por un lado, el número de

10 El 95.2\% del total de activos no solteros lo integran individuos casados. En los hombres este porcentaje aumenta hasta el $97.5 \%$, y en las mujeres disminuye hasta el $85.3 \%$.

11 RAYMOND, JL., y CASTAÑER, JM., «Algunos rasgos de la actividad y del paro según la encuesta de condiciones de vida y trabajo en España», Fundación FIES, n 33, 1988, pp. 1-17. 
Cuadro 6

TASAS DE PARO Y DE ACTIVIDAD POR GRUPOS DE EDAD, SEXO Y ESTADO CIVIL. ELCHE, 1991

\begin{tabular}{|l|c|c|c|c|c|c|c|c|}
\hline \multirow{2}{*}{$\begin{array}{c}\text { Grupos } \\
\text { de edad }\end{array}$} & \multicolumn{4}{|c|}{ SOLTEROS } & \multicolumn{4}{c|}{ NO SOLTEROS } \\
\cline { 2 - 9 } & \multicolumn{2}{|c|}{ T. de paro } & \multicolumn{2}{|c|}{ T. de actividad } & \multicolumn{2}{c|}{ T. de paro } & \multicolumn{2}{c|}{ T. de actividad } \\
\cline { 2 - 9 } V & M & V & M & V & M & V & M \\
\hline De 16 a 24 años & 36.1 & 40.9 & 63.3 & 58.1 & 26.3 & 42.9 & 96.2 & 55.2 \\
De 25 a 34 años & 31.9 & 36.1 & 91.0 & 81.1 & 20.9 & 37.5 & 98.7 & 46.5 \\
De 35 a 44 años & 31.5 & 30.7 & 86.0 & 76.6 & 19.3 & 28.4 & 98.1 & 32.8 \\
De 45 a 54 años & 33.0 & 33.2 & 76.3 & 63.7 & 21.4 & 26.1 & 93.2 & 21.9 \\
De 55 a 64 años & 27.4 & 25.5 & 57.3 & 39.1 & 24.8 & 31.7 & 65.0 & 11.9 \\
De 65 y + años & $* 13.0$ & $* 33.3$ & 10.0 & 3.5 & 24.5 & 46.5 & 3.0 & 1.08 \\
\hline Total & $\mathbf{3 4 . 5}$ & $\mathbf{3 8 . 9}$ & $\mathbf{7 0 . 0}$ & $\mathbf{6 0 . 2}$ & $\mathbf{2 1 . 2}$ & $\mathbf{3 3 . 5}$ & $\mathbf{7 5 . 8}$ & $\mathbf{2 5 . 8}$ \\
\hline Cifras totales & & & & & & & & \\
absolutas & $\mathbf{5 . 0 9 0}$ & $\mathbf{4 . 1 3 2}$ & $\mathbf{1 4 . 7 5 0}$ & $\mathbf{1 0 . 6 3 1}$ & $\mathbf{7 . 5 4 3}$ & $\mathbf{4 . 6 0 8}$ & $\mathbf{3 5 . 5 1 3}$ & $\mathbf{1 3 . 7 6 1}$ \\
\hline
\end{tabular}

* Grupos en los que se han manejado cifras absolutas poco representativas.

Fuente: Elaboración propia a partir de los datos del Censo de Población de 1991.

mujeres no solteras en el mercado de trabajo sea exiguo, y por otro, que las económicamente activas tengan más dificultades para encontrar empleo, o simplemente lo busquen con menos intensidad. En cambio, las mujeres solteras, por no estar sujetas a esas «obligaciones», participan más en la actividad económica, y por ello, las probabilidades de hallarse desocupadas son también mayores; además, la independencia económica que conlleva la soltería una vez superada la edad juvenil, propicia que las tasas de actividad se mantengan elevadas en todas las edades, hasta bien entrado los 50 años.

El análisis del paro por edades incorpora también una nueva perspectiva en la explicación del desempleo de los varones de más de 55 años, ya que a las dificultades laborales propias de este colectivo, hay que sumar la atenuación de factores que, como el deseo de casarse, o la necesidad de sustentar una familia, repercutían en el mantenimiento de tasas reducidas.

El grado de instrucción es, probablemente, la variable más significativa y de más peso en la explicación de la desigual composición del paro. Los individuos mejor instruidos son considerados los más competentes y productivos, y por lo tanto ocupan los empleos más estables $^{12}$. Por contra, las personas menos instruidas, por su escasa cualificación, están sujetas a condiciones contractuales donde predomina una mayor eventualidad e inestabilidad laboral. No obstante, todos los trabajadores, independientemente de cual sea la formación recibida, están sujetos a las leyes del mercado, y por lo tanto, es la paridad entre la oferta y la demanda de cada trabajo la que en última instancia determina las posibilidades de estar o no parado.

12 Este razonamiento apuntado por SANTILLANA DEL BARRIO, I., «Paro y estructura ocupacional de la población activa», Papeles de Economía Española, nº 8, 1981, pp. 176-193, corresponde a la visión que el enfoque tradicional tiene sobre el papel de la educación en la explicación de la desigual composición del paro. 
Cuadro 7

TASAS DE PARO POR GRUPOS DE EDAD, SEXO, Y ESTUDIOS REALIZADOS. ELCHE, 1991

\begin{tabular}{|l|c|c|c|c|c|c|r|r|}
\hline $\begin{array}{c}\text { Grupos } \\
\text { de edad }\end{array}$ & \multicolumn{2}{|c|}{$\begin{array}{c}\text { Analfabetos y } \\
\text { sin estudios }\end{array}$} & \multicolumn{2}{c|}{$\begin{array}{c}\text { Estudios de } \\
\mathbf{1}^{\mathbf{0}} \text { grado }\end{array}$} & \multicolumn{2}{c|}{$\begin{array}{c}\text { Estudios de } \\
\mathbf{2}^{\mathbf{0}} \text { grado }\end{array}$} & \multicolumn{2}{c|}{$\begin{array}{c}\text { Estudios de } \\
\mathbf{3}^{\mathbf{0}} \text { grado }\end{array}$} \\
\hline & Hombres & Mujeres & Hombres & Mujeres & Hombres & Mujeres & Hombres & Mujeres \\
\hline $16-24$ & 50.9 & 53.9 & 37.0 & 48.5 & 33.6 & 38.2 & 35.3 & 47.1 \\
$25-34$ & 36.4 & 46.6 & 28.0 & 45.3 & 22.0 & 35.0 & 10.2 & 19.2 \\
$35-44$ & 27.0 & 33.2 & 22.6 & 35.0 & 14.5 & 24.6 & 2.0 & 4.4 \\
$45-54$ & 27.1 & 30.9 & 21.0 & 27.4 & 14.0 & 25.0 & 4.0 & 4.1 \\
$55-64$ & 25.2 & 33.9 & 24.9 & 33.6 & 18.4 & 14.3 & 3.0 & $* 1.6$ \\
65 y + & 34.2 & 51.1 & 12.5 & 26.9 & 16.6 & $* 33.3$ & 3.8 & $* 20.0$ \\
\hline Total & $\mathbf{2 9 . 0}$ & $\mathbf{3 6 . 9}$ & $\mathbf{2 5 . 9}$ & $\mathbf{4 1 . 0}$ & $\mathbf{2 4 . 4}$ & $\mathbf{3 5 . 3}$ & $\mathbf{7 . 9}$ & $\mathbf{1 5 . 9}$ \\
\hline C. T. A. & $\mathbf{3 . 2 0 4}$ & $\mathbf{1 . 3 6 6}$ & $\mathbf{4 . 6 5 0}$ & $\mathbf{2 . 9 1 1}$ & $\mathbf{4 . 5 7 4}$ & $\mathbf{4 . 1 8 5}$ & $\mathbf{2 0 5}$ & $\mathbf{2 7 8}$ \\
\hline
\end{tabular}

* Grupos en los que se han manejado cifras absolutas poco representativas.

C.T.A.: Cifras Totales Absolutas.

Fuente: Elaboración propia a partir de los datos del Censo de 1991.

Cuadro 8

TASAS DE ACTIVIDAD POR GRUPOS DE EDAD, SEXO Y ESTUDIOS REALIZADOS. ELCHE, 1991

\begin{tabular}{|l|c|r|r|r|r|r|r|r|}
\hline $\begin{array}{c}\text { Grupos } \\
\text { de edad }\end{array}$ & \multicolumn{2}{|c|}{$\begin{array}{c}\text { Analfabetos y } \\
\text { sin estudios }\end{array}$} & \multicolumn{2}{c|}{$\begin{array}{c}\text { Estudios de } \\
\mathbf{1}^{\mathbf{0}} \text { grado }\end{array}$} & \multicolumn{2}{c|}{$\begin{array}{c}\text { Estudios de } \\
\mathbf{2}^{\mathbf{0}} \text { grado }\end{array}$} & \multicolumn{2}{c|}{$\begin{array}{c}\text { Estudios de } \\
\mathbf{3}^{\mathbf{0}} \text { grado }\end{array}$} \\
\hline & Hombres & Mujeres & Hombres & Mujeres & Hombres & Mujeres & Hombres & Mujeres \\
\hline $16-24$ & 77.3 & 54.7 & 85.8 & 73.7 & 59.5 & 54.5 & 50.0 & 50.4 \\
$25-34$ & 89.5 & 32.9 & 98.2 & 43.2 & 97.2 & 61.0 & 90.7 & 81.3 \\
$35-44$ & 94.4 & 26.6 & 97.7 & 31.6 & 98.5 & 47.9 & 98.1 & 82.2 \\
$45-54$ & 89.3 & 21.0 & 94.2 & 22.8 & 96.1 & 30.6 & 98.8 & 73.5 \\
$55-65$ & 60.0 & 1.9 & 69.6 & 13.0 & 77.9 & 22.1 & 92.5 & 46.8 \\
65 y + & 2.0 & 1.0 & 4.0 & 1.6 & 10.2 & 2.8 & 19.1 & 8.7 \\
\hline Total & $\mathbf{5 5 . 6}$ & $\mathbf{1 4 . 4}$ & $\mathbf{8 5 . 4}$ & $\mathbf{3 4 . 0}$ & $\mathbf{7 7 . 0}$ & $\mathbf{5 3 . 9}$ & $\mathbf{8 6 . 3}$ & $\mathbf{7 3 . 4}$ \\
\hline C. T. A. & $\mathbf{1 1 . 0 0 7}$ & $\mathbf{3 . 7 0 3}$ & $\mathbf{1 7 . 8 9 6}$ & $\mathbf{7 . 0 9 9}$ & $\mathbf{1 8 . 7 6 6}$ & $\mathbf{1 1 . 8 4 8}$ & $\mathbf{2 . 5 9 4}$ & $\mathbf{1 . 7 4 2}$ \\
\hline
\end{tabular}

C.T.A.: Cifras Totales Absolutas.

Fuente: Elaboración propia a partir de los datos del Censo de 1991. 
En cualquier caso, las tasas de paro totales de la población ilicitana (cuadro 7) descienden con el aumento del nivel de instrucción. Por sexos, la proporción de varones desocupados disminuye 4 puntos (del 29\% al 24.4\%) del grupo de los analfabetos/sin estudios a los que tienen cursos de $2^{\circ}$ grado, de manera que sólo los individuos con formación superior consiguen situarse, con un $7.9 \%$ de paro, muy por debajo del desempleo medio $(25 \%)$.

En las mujeres también se confirma esta correlación, ya que del primer nivel de estudios seleccionado al último, el desempleo cae 21 puntos. Sin embargo, aquí la tasa de paro más alta no corresponde al colectivo menos instruido. En efecto, las mujeres activas con estudios de primer grado tienen tasas de desempleo más elevadas que las que no han estudiado, a pesar de que, en principio, las primeras deben ser más productivas que las segundas. Pero, como las tasas de actividad de los que no tienen estudios son extraordinariamente bajas (un $55.6 \%$ para los hombres y un $14.4 \%$ para las mujeres; unos 20 puntos por debajo de la media de cada sexo), la situación real del desempleo en este colectivo es mucho peor de lo que las tasas del paro reflejan. Así pues, las dificultades añadidas que arrastran estas personas impide su normal integración en la vida laboral, de manera que el censo del paro se ve engordado, extraoficialmente, con las abultadas cifras del «paro desanimado».

Como se puede ver en el cuadro 8, la participación en la actividad destaca, además, por la extraordinaria dependencia de las tasas femeninas respecto al nivel de formación; por cada nivel de estudios superado esta tasa aumenta 20 puntos, entre los que tienen estudios de tercer grado las tasas de actividad son las más elevadas y la diferencia entre sexos es escasa. Entre los hombres, sólo el grupo de los que no tienen estudios se ve claramente afectado con el descenso de la proporción de activos. En conclusión, a grandes rasgos en Elche se puede confirmar que a mayor nivel de formación corresponde una mayor participación en la actividad, y una menor probabilidad de estar parado.

Lo más destacable del estudio del paro por niveles de instrucción y grupos de edades es el hecho de que los jóvenes menores de 24 años con estudios de tercer grado, aún mostrando las lógicas tasas de actividad más bajas en este tramo de edad, presentan una proporción de parados similar a la del resto de población joven. Este hecho (que trataremos con más profundidad en el apartado siguiente) es consecuencia (como ocurre en toda España) de dos acontecimientos recientes: la masiva creación de empleo poco cualificado ${ }^{13}$, y el aumento de la oferta de mano de obra con formación universitaria ${ }^{14}$. No obstante, pasados los primeros años desde la terminación de la carrera universitaria, las posibilidades de encontrar empleo son superiores en este grupo, tal y como se puede ver en el cuadro 7, en el que de la cohorte de 16-24 años a la de 25-29 años, la tasa de paro se reduce 25 puntos en los varones y 28 puntos en las mujeres. Por ello, en la actualidad, más que de individuos productivos habría que hablar de selección de individuos; la instrucción sería en este caso un indicador que utiliza el empresario para localizar a los individuos potencialmente más estables y productivos, una vez se les dote de formación específica, eliminando así incertidumbre en la contratación ${ }^{15}$.

13 TOHARIA CORTÉS, L., «El paro femenino en España: Algunos elementos para el análisis», Economía y Sociología del Trabajo, $\mathrm{n}^{\circ}$ 13, 1991, pp. 74-85.

14 En tan sólo cinco años, del Censo de población de 1991 al Padrón de Habitantes de 1996, el número de titulados universitarios de Elche ha pasado de 5.221 a 7.643 .

15 Hipótesis de la selección. SANTILLANA DEL BARRIO, I., «Paro y estructura ocupacional de la población activa», Papales de Economía Española, nº 8, 1981, pp. 176-193. 
En relación a la actividad, y de acuerdo con lo indicado, las tasas más elevadas se alcanzan a edades más tardías cuanto mayor es la formación académica. Además, se constata que los ilicitanos con un mayor nivel de instrucción permanecen activos durante más años.

Cuadro 10

TASAS DE PARO Y DE ACTIVIDAD DE LA PROVINCIA DE ALICANTE, ALICANTE CIUDAD, Y ELCHE, POR SEXO Y ESTUDIOS REALIZADOS, 1991

\begin{tabular}{|c|c|c|c|c|c|c|c|c|c|c|c|c|c|c|c|c|c|c|}
\hline \multirow{3}{*}{$\begin{array}{l}\text { Nivel de } \\
\text { Estudios }\end{array}$} & \multicolumn{6}{|c|}{ PROVINCIA } & \multicolumn{6}{|c|}{ ALICANTE } & \multicolumn{6}{|c|}{ ELCHE } \\
\hline & \multicolumn{3}{|c|}{$\begin{array}{c}\text { TASA DE } \\
\text { PARO }\end{array}$} & \multicolumn{3}{|c|}{$\begin{array}{c}\text { TASA DE } \\
\text { ACTIVIDAD }\end{array}$} & \multicolumn{3}{|c|}{$\begin{array}{c}\text { TASA DE } \\
\text { PARO }\end{array}$} & \multicolumn{3}{|c|}{$\begin{array}{c}\text { TASA DE } \\
\text { ACTIVIDAD }\end{array}$} & \multicolumn{3}{|c|}{$\begin{array}{c}\text { TASA DE } \\
\text { PARO }\end{array}$} & \multicolumn{3}{|c|}{$\begin{array}{c}\text { TASA DE } \\
\text { ACTIVIDAD }\end{array}$} \\
\hline & $\mathrm{V}$ & $\mathrm{M}$ & $\mathrm{T}$ & V & M & $\mathrm{T}$ & V & M & $\mathrm{T}$ & V & M & $\mathrm{T}$ & V & M & $\mathrm{T}$ & V & $\mathrm{M}$ & $\mathrm{T}$ \\
\hline A- S.E. & 22.2 & 29.6 & 24.2 & 49.2 & 13.4 & 28.4 & 21.7 & 25.6 & 22.9 & 48.8 & 13.1 & 26.2 & 29.0 & 36.9 & 31.0 & 55.6 & 14.4 & 32.4 \\
\hline $1^{\mathrm{er}}$ grado & 18.9 & 35.2 & 23.5 & 78.4 & 29.2 & 53.2 & 17.2 & 28.3 & 20.5 & 71.5 & 25.3 & 46.4 & 25.9 & 41.0 & 30.2 & 85.4 & 34.0 & 59.7 \\
\hline $2^{0}$ grado & 17.9 & 32.1 & 23.4 & 74.1 & 49.2 & 62.0 & 14.9 & 28.3 & 20.2 & 71.9 & 49.5 & 60.9 & 24.4 & 35.3 & 28.6 & 77.0 & 53.9 & 66.3 \\
\hline $3^{\text {er }}$ grado & 6.9 & 14.4 & 10.2 & 77.1 & 71.1 & 74.4 & 6.3 & 14.2 & 9.8 & 80.2 & 72.2 & 76.6 & 7.9 & 15.9 & 11.3 & 86.3 & 73.4 & 80.6 \\
\hline
\end{tabular}

Fuente: Elaboración propia a partir de los datos del Censo de Población de 1991.

En los distintos niveles de instrucción (cuadro 10), las tasas de paro y de actividad siempre son mayores en Elche que en Alicante y provincia, y en Elche, además, presentan una correlación inversa (el paro disminuye con la instrucción y la actividad aumenta) más marcada. Las mayores diferencias interterritoriales se dan en el grupo de los que poseen un nivel de estudios básico, sobre todo respecto a las tasas de paro femeninas y a las tasas de actividad masculinas, que difieren 13 y 15 puntos respectivamente de la ciudad de Elche a la ciudad de Alicante. Entre los analfabetos, la tasa de actividad es muy baja en los tres territorios, por lo que no hay margen para que se alcancen las diferencias registradas en la desocupación del grupo anterior.

Probablemente, la todavía escasa cualificación requerida para realizar muchas de las tareas de fabricación del calzado, hace que los ilicitanos con una reducida formación académica puedan optar a un empleo (eventual en la mayoría de los casos) con más facilidad que los alicantinos de su mismo nivel educativo, que se ven abocados a indagar en un mercado laboral más competitivo. Así, aunque en Alicante el porcentaje de población con instrucción de primer grado sea sólo 3 puntos mayor que en Elche, el resto de habitantes con estudios superiores a este nivel, que constituyen el núcleo más activo y competitivo de la oferta laboral, cubre en Alicante casi la mitad de su contingente demográfico, mientras que en Elche ni siquiera alcanza al $35 \%$ de su población.

El subconjunto de población con estudios de tercer grado forma un colectivo bastante más homogéneo, tanto respecto a la desocupación como a la participación en la actividad, aunque ambas variables representan en el municipio ilicitano porcentajes sensiblemente superiores; un $11.3 \%$ de paro y un $80.6 \%$ de actividad en Elche, frente a un $9.8 \%$ y un $76.6 \%$ en Alicante, o un $10.2 \%$ y un $74.3 \%$ en el conjunto de la provincia. 
3.3. La población parada de Elche según su experiencia profesional: parados que buscan el primer empleo y parados que han trabajado con anterioridad

La distinción de los parados en función de su experiencia profesional, no sólo confirma la peor situación laboral de la mujer ilicitana, sino que la eleva, como veremos a continuación, a una altura de auténtica marginación social.

Cuadro 11

PORCENTAJE DE PARADOS QUE BUSCAN EL PRIMER EMPLEO, SOBRE EL TOTAL DE PARADOS DE SU GRADO DE EDAD V SEXO. ELCHE. 1991

\begin{tabular}{|l|r|r|}
\hline \multicolumn{1}{|c|}{ Grupos de edad } & Hombres & Mujeres \\
\cline { 2 - 3 } & B. 1 ${ }^{\text {er }} \mathbf{E .}$ & B. 1 ${ }^{\text {er }}$ E. \\
\hline De 16 a 19 & 63.6 & 69.4 \\
De 20 a 24 & 33.2 & 39.4 \\
De 25 a 29 & 13.7 & 19.1 \\
De 30 a 34 & 3.6 & 6.0 \\
De 35 a 39 & 0.8 & 4.7 \\
De 40 a 44 & 1.1 & 3.1 \\
De 45 a 49 & 0 & 4.1 \\
De 50 a 54 & 0 & 3.0 \\
De 55 a 59 & 0 & 2.3 \\
De 60 a 64 & 0 & 1.4 \\
Más de 65 & 0 & 0 \\
\hline TOTAL & $\mathbf{1 5 . 4}$ & $\mathbf{2 6 . 3}$ \\
\hline Cifras totales absolutas & $\mathbf{1 . 9 4 5}$ & $\mathbf{2 . 2 9 6}$ \\
\hline
\end{tabular}

B.1 ${ }^{\text {er }}$ E.: Buscan el primer empleo.

Fuente: Elaboración propia a partir de los datos del Censo de Población de 1991.

En efecto, como se puede ver en el cuadro 11, donde se presenta el porcentaje de parados que buscan el primer empleo entre los parados de su grupo de edad y sexo (y por defecto los parados que han trabajado antes), el $26.3 \%$ de las mujeres desocupadas no ha trabajado nunca, frente a un $15.4 \%$ de los hombres parados; además, para cada uno de los grupos de edad seleccionados el porcentaje siempre es superior en el colectivo femenino. Por otro lado, a partir de los 45 años ya no hay hombres sin experiencia laboral, mientras que las mujeres retrasan esa circunstancia hasta bien entrados las 60 años. A pesar de estas diferencias, como apunta María Pazos Morán ${ }^{16}$, este dato no llega a ser representativo de la

16 PAZOS MORÁN, M., «Las mujeres y el empleo en España. Elementos para un balance 1987-1990» Economía y sociología del trabajo, $\mathrm{n}^{\circ}$ 13-14, 1991, pp. 74-85. 
Cuadro 12

PORCENTAJE DE MUJERES EN LOS DOS TIPOS DE PARADOS. ELCHE. 1991

\begin{tabular}{|l|r|r|}
\hline \multicolumn{1}{|c|}{ Grupos de edad } & H.T.A. & B. 1 $^{\text {er }}$ E. \\
\hline De 16 a 19 & 46.2 & 52.7 \\
De 20 a 24 & 46.7 & 53.3 \\
De 25 a 29 & 46.6 & 56.4 \\
De 30 a 34 & 42.6 & 55.7 \\
De 35 a 39 & 34.8 & 76.6 \\
De 40 a 44 & 32.8 & 59.2 \\
De 45 a 49 & 26.0 & 100.0 \\
De 50 a 54 & 21.4 & 88.9 \\
De 55 a 59 & 19.7 & 71.4 \\
De 60 a 64 & 23.1 & 100.0 \\
Más de 65 & 50.0 & 0 \\
\hline TOTAL & $\mathbf{3 7 . 6 0}$ & $\mathbf{5 4 . 1 3}$ \\
\hline Cifras totales absolutas & $\mathbf{6 . 4 4 4}$ & $\mathbf{2 . 2 9 6}$ \\
\hline
\end{tabular}

B.1 er E.: Buscan el primer empleo.

H. T. A.: Han trabajado antes.

Fuente: Elaboración propia a partir de los datos del Censo de Población de 1991.

distinta magnitud de los colectivos de parados de uno y otro sexo, ya que al ser también mucho mayor la tasa de paro femenina, es como si estuviésemos midiendo en distintas unidades; tasas realmente comparables son las de parados en busca del primer empleo sobre activos, que en el caso de Elche es del $9.9 \%$ para las mujeres y del $3.9 \%$ para los hombres.

El cuadro 12 refleja el porcentaje de mujeres en los dos tipos de parados, en los que han trabajado anteriormente y en los que buscan su primer empleo, y por defecto, la proporción de hombres en ambas variables. En este cuadro se advierte que las mujeres sin experiencia laboral, que representan un $54.3 \%$ del total de este grupo, son mayoría en todos las tramos de edad hasta los 64 años. Asimismo, es de gran interés comprobar cómo pasados los 35 años de edad, y sobre todo los 45, las mujeres copan, casi en su totalidad, la proporción de individuos que buscan su primer trabajo.

En relación a esta circunstancia, pero referido al paro femenino del estado español, Pazos Morán señala la gravedad del caso de las mujeres paradas que se reincorporan, tras la dedicación a la crianza de los hijos durante 10 ó 15 años, a su profesión, enfrentándose al mercado con una formación precaria, y sin posibilidades de acceder a la contratación incentivada, por sobrepasar los límites de edad y/o por haber transcurrido 4 años desde la obtención del correspondiente título ${ }^{17}$. Pero en Elche, además, hay que añadir el caso, muy numeroso, de mujeres que después de permanecer varios años trabajando en la economía

17 PAZOS MORÁN, M., «Las mujeres y el empleo en España. Elementos para un balance 1987-1990» Economía y sociología del trabajo, $\mathrm{n}^{\circ}$ 13-14, 1991, pp. 74-85. 
sumergida, intentan, con escaso éxito, encontrar un empleo legal. Prueba de esta (re)incorporación tardía al mercado laboral, y de la probable mayor estancia en esta situación de búsqueda, es que las mujeres sin experiencia tienen más edad que los varones sin experiencia; el 17\% de los hombres tiene más de 25 años, frente al $21 \%$ de las mujeres.

Por lo que respecta al subconjunto de parados que ha trabajado alguna vez, la situación es totalmente inversa, ya que la mitad de las mujeres de este subconjunto (en el que representan un el $37.6 \%$ del total) tiene menos de 29 años, mientras que sólo una tercera parte de los hombres es menor de esta edad. Estas cifras ponen de manifiesto que la rotación laboral comienza a edades más tempranas en el colectivo femenino.

El cuadro 13 nos muestra el porcentaje de parados que busca su primer empleo y el porcentaje de los que han trabajado antes, en la provincia de Alicante, Alicante ciudad y Elche. Precisamente es el municipio ilicitano el que tiene la mayor proporción de parados que han trabajado alguna vez (80.1\%), y por ende, el menor porcentaje de desocupados sin experiencia laboral (19.9\%). En cambio, en Alicante los que buscan el primer empleo (un $27.1 \%$ ) tienen mucho más peso en el conjunto total de parados. Estas diferencias son consecuencia de la, ya citada, mayor rotación laboral del mercado de trabajo ilicitano. Pero además, como el grupo de los activos que no ha trabajado nunca está compuesto, básicamente, por jóvenes menores de 24 años, y éstos tienen un mayor nivel educativo en Alicante, el elevado porcentaje de este colectivo en la capital de la provincia respecto a la ciudad de Elche, es también resultado de las mayores dificultades que los jóvenes más instruidos tienen para encontrar su primer empleo.

Cuadro 13

PORCENTAJE DE PARADOS QUE BUSCAN EL PRIMER EMPLEO Y QUE HAN TRABAJADO ANTES SOBRE EL TOTAL DE PARADOS, 1991

\begin{tabular}{|c|c|c|c|c|c|c|}
\hline & \multicolumn{6}{|c|}{ Porcentaje de uno y otro tipo de paro sobre el total de parados } \\
\hline & \multicolumn{2}{|c|}{ HOMBRES } & \multicolumn{2}{|c|}{ MUJERES } & \multicolumn{2}{|c|}{ TOTAL } \\
\hline & H. T. A. & B. $\mathbf{1}^{\text {er }} \mathbf{E}$. & H. T. A. & B. $\mathbf{1}^{\text {er }} \mathbf{E}$. & H. T. A. & B. $\mathbf{1}^{\mathrm{er}} \mathbf{E}$. \\
\hline PROVINCIA & 80.4 & 19.6 & 71.8 & 28.2 & 76.6 & 23.4 \\
\hline ALICANTE & 77.7 & 22.3 & 68.0 & 32.0 & 72.9 & 27.1 \\
\hline ELCHE & 84.6 & 15.4 & 73.7 & 26.3 & 80.1 & 19.9 \\
\hline
\end{tabular}

H. T. A.: Han trabajado antes.

B. $1^{\text {er }}$ E.: Buscan primer empleo.

Fuente: Elaboración propia a partir de los datos del Censo de Población de 1991

\section{Distribución espacial de la tasa de paro en el municipio de Elche}

Los valores medios locales y las disparidades sociodemográficas entre entidades supramunicipales no deben esconder la consideración del ente urbano como un espacio de marcada heterogeneidad interna. De hecho, las diferencias intraurbanas de una ciudad como Elche (188.062 habitantes municipales en 1991, y 191.798 en 1996) exceden en mucho la tradicional oposición entre la población rural y la población urbana. Aun así, un primer aná- 
lisis del desempleo del municipio a nivel de sección padronal, nos permite llegar a esa primera diferenciación: las secciones del distrito rural presentan una tasa media de parados $(21 \%)$ inferior a la media de la ciudad de Elche (30\%), y cifras mucho más uniformes que las que observamos en las secciones urbanas, seguramente debido a que el campo tiene una naturaleza agraria más o menos común para toda la sociedad de este medio, mientras que la ciudad acoge grupos sociales y actividades más heterogéneas, lo que propicia, a su vez, situaciones laborales más dispares.

No obstante, en la baja tasa de paro del distrito rural (cuya población en 1991 era de 21.741 habitantes) intervienen también los porcentajes de secciones como las del núcleo urbano de Torrellano (2.855 habitantes), o la del centro turístico de Arenals del Sol (1.158 habitantes). Sin embargo, únicamente la sección número 2 , que coincide con la pedanía rural de Carrús (1.443 habitantes), podría cuestionar con su alta tasa de desempleo (37.8\%) la supuesta uniformidad de los datos socioeconómicos referidos al medio rural; pero esta última entidad incluye una porción de espacio periurbano, pequeña en extensión pero con un importante peso demográfico en la sección padronal (casi la mitad): la orla suburbana del barrio del Cementeri. El barrio del Cementeri, fruto del desordenado crecimiento que vivió la ciudad desde mitad de los años 40 , fue ocupado por inmigrantes con escaso poder adquisitivo; en muchos casos, ante la imposibilidad de hacer frente al pago de un piso, recurrieron al chabolismo y a la vivienda de autoconstrucción. Esta problemática urbanística, que ha llegado hasta nuestros días, ha favorecido la aparición de una conflictividad social que es, en parte, causante de las elevadas tasas de desempleo de esta zona.

El resto de secciones rurales registran una tasa de paro inferior al $26 \%$, y más de la mitad, 9 secciones sobre un total de 17, no sobrepasa el 19\%, siendo la partida de La Baía (Alta y Baixa), con un $11.71 \%$ de paro, la sección de todo el municipio ilicitano con una menor proporción de parados entre su población activa. Las causas que explican este menor desempleo entre los activos del medio rural son variadas. En primer lugar, la tasa de actividad de la población rural $(51 \%)$ es inferior a la tasa de actividad de los habitantes de la capital municipal (61\%), así que la oferta de trabajadores censados en el campo ya es en principio menor. En segundo lugar, la estructura minifundista de las explotaciones agrarias del campo de Elche favorece el autoempleo. El Censo Agrario de 1989 contabiliza 3.967 explotaciones agrarias para un total de 3.963 titulares, un 65\% (2.560) de los cuales tiene como ocupación principal sólo la explotación. El Censo de Población de 1991, por su parte, arroja una cifra de cerca de 2.500 ocupados en la agricultura (cifra sensiblemente inferior a la de propietarios con dedicación exclusiva inscritos en el Censo Agrario), de los que 1.500 tienen su residencia en el distrito rural. Sin embargo, esta última cifra sólo representa el $20 \%$ del total de ocupados del medio rural, y aunque este porcentaje no comprenda a los activos en su conjunto, es suficientemente expresiva como para pensar que existen otros factores que rebajan la tasa de paro.

Entre esas otras causas está la cada vez mayor presencia en el medio rural de individuos con un alto poder adquisitivo (y por lo tanto con una buena situación laboral), que llegaron desde la ciudad, primero como habitantes de segunda residencia y después como residentes fijos, en busca de una mayor calidad de vida. Por último, hay que destacar el hecho de que la crisis agrícola, a diferencia de la que sufrió la industria a mediados de los años setenta, no generase una gran bolsa de parados. En efecto, esta crisis, que afectó (y afecta todavía hoy) fundamentalmente a la agricultura familiar, coincidió con la expansión de la industria del calzado, lo cual favoreció el trasvase de trabajadores del sector agrario al sector industrial. Como muchos de estos trabajadores fijaron su residencia en la ciudad, 
la población del medio rural resultante no fue tan afectada por la posterior crisis de la manufactura del calzado.

El reparto espacial de la tasas de paro en el interior de la ciudad de Elche distingue, a grandes rasgos, las siguientes áreas:

1. Espacio central, ocupado por las secciones del centro histórico, y por las secciones de la margen derecha del río Vinalopó más próximas al casco antiguo, con tasas de paro reducidas (menores del $18 \%$ ).

2. Zona en torno a la anterior, con diversidad de tasas de paro, pero en la que abundan las secciones con porcentajes de paro superiores a la media.

3. Enclaves y barrios periféricos muy afectados por el desempleo (con tasas superiores al $34 \%)$.

La edad, el sexo, el estado civil, o la instrucción recibida son características sociodemográficas que influyen de manera decisiva en la estructura y en la virulencia del desempleo. Pero es la profesión y la actividad económica del establecimiento donde se trabaja, y las condiciones contractuales del empleo, lo que en última instancia determina la situación laboral de la persona activa. Ni que decir tiene que en Elche el sector industrial es el que genera un mayor número de trabajadores sin empleo. De hecho, aunque los datos sobre la actividad del establecimiento de trabajo aparezcan en el Censo de Habitantes asociados a la población ocupada, en vez de a la activa, en la que se incluye de facto a los parados, se puede afirmar que la mayoría de las secciones (el $72.7 \%$ de las mismas) que exceden la media local de ocupados en la industria $(43.61 \%)$, superan igualmente la media de parados del municipio. Este hecho, como hemos podido comprobar, guarda relación con la reestructuración industrial iniciada a mediados de los años setenta, y con la actual flexibilización del mercado laboral de la industria del calzado, es decir, subempleo, trabajo eventual, prácticas informales, etc.

En el otro extremo se hallan las secciones en las que predomina la población ocupada en el sector terciario, la mayoría de las cuales (73.2\%) presentan tasas de paro inferiores a la media de la localidad (28.6\%). Existen, sin embargo, algunos espacios donde la baja cualificación de los servicios (sujetos, por lo tanto, a unas peores condiciones laborales), hace que el número de parados sea mucho mayor. Esto es lo que sucede en varios sectores de los barrios de Carrús, Altabix, la Rata, y sobre todo de els Palmerals, donde la sección número 11, la que ostenta la mayor tasa de paro de Elche, tiene por contra, casi un $50 \%$ de empleados en el sector servicios, es decir, más de 6 puntos por encima del valor medio de ocupados en este sector (43.95\%).

Uno de los datos demográficos con mayor precisión para individualizar las secciones con altas tasas de paro es el de la inmigración. A grandes rasgos, se puede afirmar que las secciones con altos porcentajes de inmigrados se ven más afectadas por el desempleo que las secciones donde predomina la población autóctona. La proporción es la siguiente: el $70 \%$ de la secciones padronales habitadas en más de un $50 \%$ por población inmigrada, tienen índices de parados superiores a la media de la ciudad (28.6\%); en cambio, el $80 \%$ de las secciones en las que se supera la media municipal de población nacida en Elche $(50 \%)$, tiene porcentajes inferiores a esa tasa media. Así pues, los barrios creados (en la década de los años 60 y 70, periodo de mayor expansión económica y urbanística de la ciudad) ex profeso para acoger a inmigrantes, son los que sufren las tasas de paro más elevadas: la Rata, 45.1\%; els Palmerals, 43.0\%; Casablanca, 39.8\%; Carrús est, 34.5\%; San Crispín, 33,8\%; 


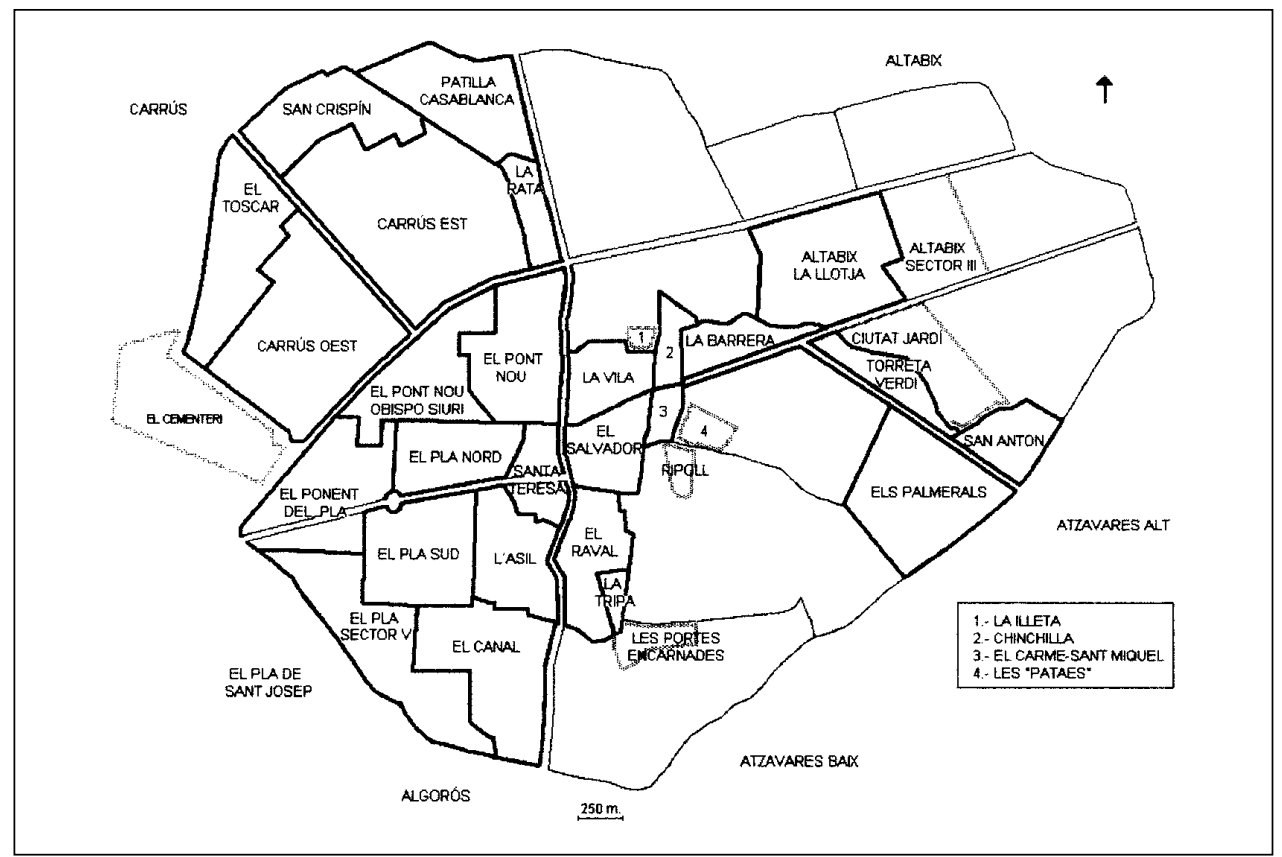

MAPA 1. Barrios de la ciudad de Elche.

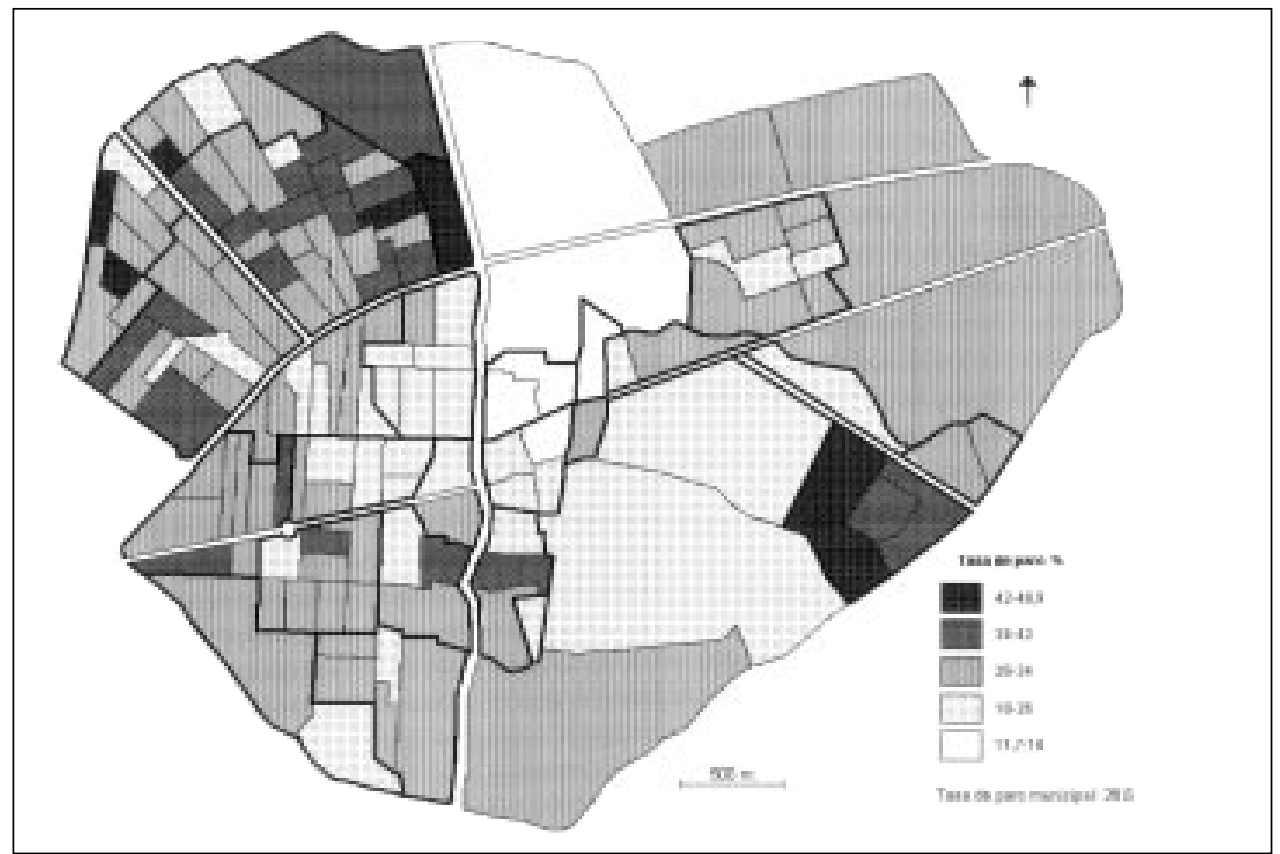

MAPA 2. Distribución de las tasas de paro por secciones en la ciudad de Elche. 1991. 


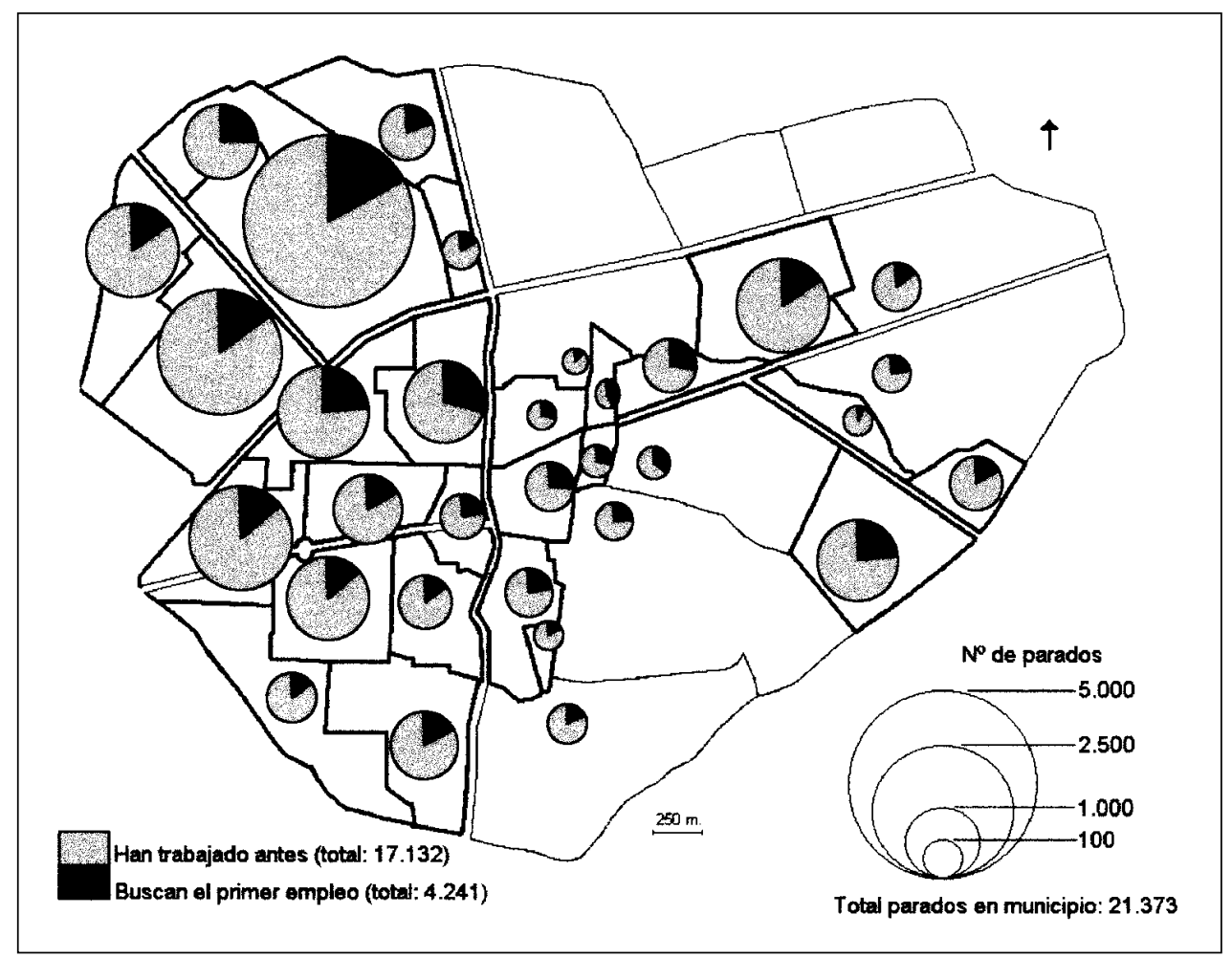

MAPA 3. Distribución de la población parada por barrios, en totales y en proporción de los que buscan el primer empleo y de los que han trabajado con anterioridad. Elche, 1991.

el Toscar 33,5\%, etc. Por el contrario, el espacio central de la ciudad, donde se hallan los barrios históricos de la Vila (12\% de paro), el Salvador (20.5\%), el Carme-Sant Miquel (21.7\%), la Illeta (15.3\%) etc., junto con otros centrales de configuración más reciente, como el Pont Nou (22.3\%) o el Pla Nord (22.1\%), constituye la zona de Elche menos afectada por el desempleo.

Este desigual reparto del paro en función de la mayor o menor proporción de inmigrantes, se debe, en primer lugar, a que éstos ocupan básicamente empleos industriales, y empleos terciarios poco cualificados. En segundo lugar, la oferta de mano de obra en las secciones donde predomina la población inmigrante es mayor; tradicionalmente, la existencia de menos estudiantes entre los hijos de inmigrados mayores de 16 años, y la mayor participación de la mujer en el trabajo ${ }^{18}$, disparaban las tasas de actividad de estas secciones. No obstante, aunque todavía se mantiene esta característica, en la actualidad a mayor porcentaje de inmigrantes no corresponde necesariamente una mayor proporción de activos. En efecto, hay barrios ocupados casi en su totalidad por inmigrados, como San Antón (el 78\% de su población es inmigrante) o la Sagrada Familia, en el interior de Carrús Oest,

18 GOZÁLVEZ PÉREZ, V., La ciudad de Elche, Valencia, 1976, p. 290. 
donde la falta de viviendas nuevas ha provocado un éxodo de parte de la población joven ${ }^{19}$ potencialmente activa. Buen ejemplo de ello, es que el barrio de San Antón ha pasado de tener una tasa de actividad cinco puntos superior a la media de Elche en $1970^{20}$, a presentar en 1991 un porcentaje de activos inferior en más de 15 puntos al porcentaje medio de la ciudad. Por último, los menores niveles de estudios de la población inmigrada, como vimos en su momento, también contribuye a engrosar las cifras del paro.

\subsection{El paro Juvenil (de 16 a 24 años) y su distribución en los barrios de la ciudad}

En el conjunto del municipio se encuentran en paro el $44 \%$ de los ilicitanos entre 16 y 19 años y el 35\% de los que tienen entre 20 y 24 años. Es decir, 7.074 jóvenes no tienen empleo, lo que representa el $38 \%$ de la población activa joven y el $33 \%$ del conjunto de la población total parada.

Lamentablemente, la falta de datos sobre el paro juvenil a una escala inferior a la municipal, nos impide realizar un análisis directo de las diferencias intraurbanas de este tipo de desempleo. En cualquier caso, a través de las cifras del grupo de parados que buscan su primer empleo (dato existente para todas las secciones padronales) podemos acercarnos, aunque parcialmente, a este estudio, ya que el $80 \%$ de sus integrantes tienen menos de 24 años. Aún así, de los 7.074 jóvenes parados con que cuenta Elche en 1991, algo más de la mitad (el 52\%) quedan fuera de los que buscan el primer empleo, ya que estas personas, por haber trabajado con anterioridad, se mezclan con el resto de población con experiencia laboral.

Salvando estas dificultades, los resultados a nivel de barrio nos ofrecen la posibilidad de comprobar como existe una cierta relación inversa, entre las tasas de paro y los porcentajes de los que buscan su primer empleo. Prueba de ello es que 6 de los 7 barrios con una menor proporción de desocupados de todo Elche, tienen un tanto por cien de parados sin experiencia laboral superior al de la media de la ciudad (20.9\%), mientras que casi el 80\% de los barrios con tasas de paro superiores a la tasa municipal, presentan porcentajes de ese tipo de desempleo inferiores al valor medio.

Básicamente, estas diferencias son resultado de la instrucción y de la preparación profesional que los jóvenes han adquirido a lo largo de su periodo formativo. Como se puede observar en el cuadro 16, las tasas de paro no respetan excesivamente a los jóvenes con más estudios, de hecho el panorama es especialmente grave para el segmento de los licenciados en facultades universitarias, entre los cuales la tasa de paro se halla en torno al $60 \%$, porcentaje sólo superado por el del grupo de los analfabetos. El desempleo tiene una incidencia mucho menor sobre el resto de universitarios, aunque las tasas de paro más bajas corresponden a los titulados en Formación Profesional y Bachillerato, y a los que poseen otras enseñanzas de $2^{\circ}$ grado. Por debajo de este nivel la tasa vuelve a aumentar, situándose en un $41.8 \%$ para los jóvenes con estudios de primer grado, y en un $50.7 \%$ para los que no tienen estudios. Por último, los jóvenes analfabetos, con un $68 \%$ de activos desocupados, representan el colectivo más problemático, aunque, afortunadamente, en cifras absolutas no constituyen un grupo muy numeroso (203 individuos en el conjunto del municipio).

19 PALAZÓN FERRANDO, S., «Cambios en la población de Elche entre 1970 y 1986. Un ejemplo de la crisis demográfica del País Valenciano», Investigaciones Geográficas, n 7, 1989, pp. 191-204.

20 GOZÁLVEZ PÉREZ, V., La ciudad de Elche, Valencia, 1976, p. 290. 
En cuanto a la participación en el mercado laboral, los individuos más activos son, de mayor a menor, los que tienen estudios de primer grado, los que no han estudiado, los que han cursado el primer ciclo del segundo grado, y curiosamente, los jóvenes que han realizado la carrera en una facultad universitaria, todos ellos con porcentajes superiores a la tasa de actividad media. Así pues, a excepción de este último grupo, y el de los analfabetos, los individuos con estudios superiores al mínimo obligatorio son los que poseen las tasas de actividad más bajas.

De la visión conjunta del paro y de la actividad, hay que resaltar las elevadas tasas del grupo de los que tienen estudios en facultades universitarias. Quizás ello se deba a que muchas de estas personas completan sus conocimientos adquiridos durante la carrera con nuevos cursos («masters», cursos de postgrado, idiomas extranjeros, etc.), alargando una

Cuadro 14

BARRIOS CON TASAS DE PARO INFERIORES A LA MEDIA DE ELCHE, 1991

\begin{tabular}{|l|c|c|c|c|}
\hline \multicolumn{1}{|c|}{ BARRIOS } & T. de paro & T. de Act. & \% de desocupados \\
\cline { 2 - 5 } & & & ${\text { B. } \mathbf{1}^{\text {er }} \text { E. }}^{\text {H. T. A. }}$ \\
\hline La Vila & 12.1 & 42.5 & 28 & 72 \\
La Illeta & 15.3 & 45.9 & 12 & 88 \\
Chinchilla & 17.5 & 43.2 & 42 & 58 \\
Les «Pataes» & 20.3 & 41.5 & 35 & 65 \\
El Salvador & 20.5 & 49.4 & 28 & 72 \\
El Carme-Sant Miquel & 21.7 & 47.2 & 29 & 71 \\
Ripoll & 21.5 & 57.6 & 24 & 76 \\
Torreta Verdi & 21.9 & 56.3 & 9 & 91 \\
El Pla Nord & 22.1 & 51.4 & 18 & 82 \\
El Pont Nou & 22.3 & 53.0 & 29 & 71 \\
La Barrera & 23.3 & 52.1 & 28 & 72 \\
La Tripa & 24.1 & 52.6 & 18 & 82 \\
Santa Teresa & 24.6 & 48.4 & 23 & 77 \\
Altabix-La Llotja & 25.9 & 59.3 & 16 & 84 \\
El Pla-Sector V & 25.6 & 61.8 & 16 & 84 \\
El Pont N.-Obispo S. & 28.3 & 53.1 & 24 & 76 \\
Les Portes Encarnades & 28.3 & 51.1 & 17 & 83 \\
Ciutat Jardí & 28.3 & 56.6 & 23 & 77 \\
El Raval & 28.4 & 48.2 & 22 & 78 \\
\hline TOTAL & $\mathbf{2 4 . 2}$ & $\mathbf{5 2 . 5}$ & $\mathbf{2 3 . 2}$ & $\mathbf{7 6 . 7}$ \\
\hline Media de Elche & $\mathbf{2 8 . 6}$ & $\mathbf{5 3 . 8}$ & $\mathbf{1 9 . 8}$ & $\mathbf{8 0 . 1}$ \\
\hline
\end{tabular}

Fuente: Elaboración propia a partir de los datos del Censo de Población de 1991. 
Cuadro 15

BARRIOS CON TASAS DE PARO SUPERIORES A LA MEDIA DE ELCHE, 1991

\begin{tabular}{|l|c|c|c|c|}
\hline \multirow{2}{*}{ BARRIOS } & T. de paro & T. de Act. & \multicolumn{2}{c|}{ \% de desocupados } \\
\cline { 2 - 5 } & & & B. 1 ${ }^{\text {er }}$ E. & H. T. A. \\
\hline La Rata & 45.1 & 53.1 & 19 & 81 \\
Els Palmerals & 43.0 & 58.9 & 24 & 76 \\
Patilla-Casablanca & 39.8 & 55.4 & 21 & 79 \\
Carrús Est & 34.5 & 53.9 & 17 & 83 \\
San Crispín & 33.8 & 54.2 & 25 & 75 \\
El Toscar & 33.5 & 55.4 & 16 & 84 \\
El Ponent del Pla & 32.4 & 55.6 & 15 & 85 \\
El Pla Sud & 30.7 & 54.8 & 14 & 86 \\
Carrús Oest & 30.6 & 57.9 & 15 & 85 \\
San Antón & 30.6 & 47.7 & 17 & 83 \\
L'Asil & 30.1 & 51.1 & 15 & 85 \\
Altabix-Sector III & 29.2 & 67.9 & 16 & 84 \\
El Canal & 28.6 & 55.7 & 18 & 82 \\
\hline TOTAL & $\mathbf{3 3 . 2}$ & $\mathbf{5 5 . 2}$ & $\mathbf{1 7 . 2}$ & $\mathbf{8 2 . 8}$ \\
\hline Media de Elche & $\mathbf{2 8 . 6}$ & $\mathbf{5 3 . 8}$ & $\mathbf{1 9 . 8}$ & $\mathbf{8 0 . 1}$ \\
\hline
\end{tabular}

Fuente: Elaboración propia a partir de los datos del Censo de Población de 1991.

B. $1^{\text {er }}$ E.: Buscan el primer empleo.

H. T. A.: Han trabajado antes.

preparación académica que en muchos casos se hace coincidir con la primera inscripción en las listas del paro. De hecho, alrededor del 80\% de los jóvenes universitarios parados se encuentran en situación de búsqueda del primer empleo, mientras que en el resto de grupos, este porcentaje disminuye por debajo del $50 \%$.

Por lo tanto, se puede afirmar que a mayores niveles de estudios corresponden mayores posibilidades de hallarse en paro como desocupado sin experiencia profesional. Como estas cifras están referidas a la población de 16 a 24 años, se podría pensar que esa afirmación es consecuencia de que los jóvenes finalizan sus estudios superiores alrededor de los 24 años, por lo que no han tenido tiempo para modificar las estadísticas del paro, que los cataloga como parados en busca del primer empleo. Sin embargo, si a los datos analizados les añadimos los de la cohorte de 25 a 29 años los resultados no varían excesivamente; el $75 \%$ de los parados que poseen estudios de tercer grado buscan el primer empleo, mientras que para los demás colectivos, los porcentajes se hallan entre el 33\% y el $36 \%$.

Así pues, los jóvenes de los barrios centrales de la ciudad, que debido al poder adquisitivo de sus familias tienen más facilidades para realizar estudios de grado superior (las altas cifras de titulados respecto a otros barrios así lo demuestra), y menos necesidades de participar en un mercado laboral inseguro, demandan, en consonancia con su perfil 
Cuadro 16

TASAS DE PARO Y DE ACTIVIDAD DE LA POBLACIÓN JOVEN ENTRE

16 Y 24 AÑOS DE EDAD, SEGÚN NIVEL DE FORMACIÓN, Y PORCENTAJE DE LOS QUE BUSCAN EL PRIMER EMPLEO SOBRE EL TOTAL DE PARADOS DE SU GRUPO. ELCHE, 1991

\begin{tabular}{|c|c|c|c|c|c|c|c|c|c|c|}
\hline \multirow{2}{*}{\multicolumn{2}{|c|}{ ESTUDIOS }} & \multicolumn{3}{|c|}{ T. DE PARO } & \multicolumn{3}{|c|}{ T. DE ACTIVIDAD } & \multicolumn{3}{|c|}{$\%$ B. $1^{\text {er }} \mathbf{E}$. } \\
\hline & & H & M & $\mathrm{T}$ & $\mathrm{H}$ & M & $\mathrm{T}$ & $\mathbf{H}$ & M & $\mathrm{T}$ \\
\hline \multicolumn{2}{|l|}{ TOTAL } & 35.3 & 41.2 & 38.0 & 65.1 & 57.7 & 61.5 & 45.1 & 51.6 & 48.3 \\
\hline \multicolumn{2}{|l|}{ Analfabetos } & 79.0 & 47.6 & 68.7 & 58.1 & 28.3 & 43.5 & 41.2 & 70.0 & 47.7 \\
\hline \multicolumn{2}{|l|}{ Sin estudios } & 48.1 & 54.4 & 50.7 & 80.0 & 58.4 & 69.4 & 41.1 & 62.3 & 50.5 \\
\hline \multicolumn{2}{|c|}{ Estudios de primer grado } & 37.1 & 48.5 & 41.8 & 85.8 & 73.7 & 80.3 & 41.4 & 50.9 & 45.9 \\
\hline \multirow{3}{*}{$\begin{array}{l}\text { Estudios de } \\
\text { segundo } \\
\text { grado }\end{array}$} & Primer ciclo & 34.5 & 40.5 & 37.6 & 69.0 & 62.6 & 65.9 & 45.5 & 50.9 & 48.2 \\
\hline & Segundo ciclo & 28.9 & 31.9 & 30.4 & 41.0 & 40.3 & 40.7 & 51.1 & 45.8 & 48.3 \\
\hline & Otros & 28.6 & 26.1 & 26.8 & 18.1 & 36.2 & 27.6 & 50.0 & $* 80.0$ & 61.0 \\
\hline \multirow{3}{*}{$\begin{array}{l}\text { Estudios de } \\
\text { tercer } \\
\text { grado }\end{array}$} & Escuela universitaria & 30.0 & 31.5 & 30.7 & 45.5 & 41.1 & 43.2 & 55.2 & 69.0 & 62.0 \\
\hline & Facultad & 47.2 & 66.2 & 58.0 & 59.5 & 67.6 & 63.9 & 84.0 & 93.6 & 90.0 \\
\hline & Otros* & --- & 5.1 & 40.0 & 75.0 & 87.5 & 83.3 & ---- & 100.0 & 100.0 \\
\hline
\end{tabular}

* Grupos en los que se han manejado cifras absolutas poco representativas.

Fuente: Elaboración propia a partir del censo de 1991.

académico y/o con esa posición económica ventajosa, trabajos más estables y con salarios más elevados, y por ello más difíciles de conseguir en el contexto socioeconómico actual. De hecho, es de suponer que en barrios centrales como la Vila, el Salvador, o el Pont Nou, estas personas permanecen durante más tiempo inscritas en las listas del INEM. En los barrios periféricos, sin embargo, los jóvenes suelen finalizar sus estudios a edades más tempranas, obteniendo una preparación enfocada hacia trabajos menos cualificados, lo que les permite alcanzar con menores dificultades un mercado laboral dinámico, pero de empleo preferentemente eventual. La escasa estabilidad de estos empleos hace, por lo tanto, que la mayoría de los jóvenes activos de estos barrios terminen engordando de nuevo las estadísticas del desempleo, aunque esta vez como parados con experiencia laboral.

Por último, en barrios como els Palmerales, donde el absentismo escolar contribuye a aumentar las cifras de personas analfabetas y sin estudios (que ya superan el $48 \%$ del total de la población de más de 10 años de esta zona), los jóvenes encuentran dificultades añadidas para integrarse en el mercado de trabajo. Aquí, la tasa de paro es elevadísima (43.\%), y el porcentaje de los que buscan su primer empleo supera, por tres puntos, la media de Elche. Aunque esta última cifra se asemeje a la de los barrios del centro de la ciudad, en els Palmerales la situación de partida es tan radicalmente opuesta que los jóvenes también alargan el periodo de búsqueda del primer trabajo, pero en este caso por la escasa o nula formación académica y profesional que poseen. Y esto en el mejor de los casos, ya que la 
mayor parte de la población de este barrio que sin padecer taras físicas ni síquicas mantiene un estado de «ocio permanente», son precisamente individuos jóvenes ${ }^{21}$.

De toda esta explicación se puede concluir que la escasez de trabajo, común para toda la sociedad, no repercute por igual sobre el conjunto de la población juvenil: «No es lo mismo un joven sin trabajo después de haber acabado sus estudios de licenciatura o de carreras técnicas, procedente, en la mayor parte de los casos, de medios culturales bien cultivados, que el joven que procede de sectores populares marginados o afectados por el paro endémico» ${ }^{22}$.

\section{Bibliografía}

BAYLINA, MIREIA, «Geografía de la producció, flexibilitat en el mercat de treball i relacions de gènere. L'exemple del treball industrial a domicili», Cuadernos de Geografía, $\mathrm{n}^{\circ}$ 55, pp. 45-61, Valencia 1994.

CÁRITAS: Dossier Empleo: Economía social, Autoempleo juvenil, Madrid, 1987, p. 184.

GARCÍA, J. NIETO P., «Incapacidad del Sistema económico para generalizar el bienestar: el paro y los jóvenes desocupados», Cáritas: Dossier-El Paro II , 1986, pp. 55-62.

GARCÍA, J., POLO, C., RAYMOND, JL., «Principales rasgos del desempleo masculino en España», Papeles de Economía Española, nº 26, 1986, pp. 81-107.

GOZÁLVEZ PÉREZ, VICENTE: La ciudad de Elche, Dpto. de Geografía, Universidad de Valencia, 1976, p. 290.

GOZÁLVEZ PÉREZ, VICENTE: El Bajo Vinalopó. Geografía Agraria, Dpto. de Geografía, Universidad de Valencia, 1977, p. 270.

GOZÁLVEZ PÉREZ, VICENTE (Dir.): Atlas sociodemográfico de la ciudad de Alicante, Instituto de Estudios «Juan Gil-Albert», Diputación Provincial de Alicante, 1987, p. 143.

LÓPEZ FERNÁNDEZ, B., «La gradación del envejecimiento en los espacios intraurbanos. Estructuras demográficas y crecimiento urbano en Gijón», Eria, 1988, pp. 201-234.

PALAZÓN FERRANDO, S., «Cambios en la población de Elche entre 1970 y 1986. Un ejemplo de la crisis demográfica del País Valenciano», Investigaciones Geográficas, $\mathrm{n}^{\mathbf{0}}$ 7, 1989, pp. 191-204.

PAZOS MORÁN, M., «Las Mujeres y el Empleo en España. Elementos para un Balance 1987-1990», Economía y Sociología del Trabajo, n 13-14, Septiembre/Diciembre 1991, pp. 88-102.

TOHARIA CORTÉS, L. «El Paro femenino en España: Algunos elementos para el análisis», Economía y Sociología del Trabajo, no 13-14, Septiembre/Diciembre 1991, pp. 74-85.

RAYMOND, JL., y CASTAÑER, JM., «Algunos rasgos de la actividad y del paro según la encuesta de condiciones de vida y trabajo en España», Fundación FIES, Obra Social de la Confederación de Cajas de ahorro, no 33, 1988.

SANCHÍS, ENRIC: La otra economía. Trabajo Negro y sector informal, Valencia, 1988, p. 420.

SANTILLANA DEL BARRIO, I., «Paro y Estructura Ocupacional de la Población Activa», Papeles de Economía Española, nº 8, Madrid, 1981, pp. 176-193.

SEBASTIÁN ALCARAZ, R., «La industria del calzado en la provincia de Alicante: características de su evolución reciente (1970-1991)», Investigaciones Geográficas, no ${ }^{\circ}$, 1997, pp. 81-98.

21 SAN JOSÉ, P., El Barrio de los Palmerales, inédito.

22 GARCÍA-NIETO PARÍS, Joan N., «Incapacidad del sistema económico para generalizar el bienestar : el paro y los jóvenes desocupados». Cáritas: Dossier-El Paro II, 1986, pp. 55-62. 